\title{
Persistence is futile: Chasing of past performance in repeated investment choices ${ }^{1}$
}

\author{
Leonardo Weiss-Cohen $^{(a)}$, Philip W.S. Newall(b) ${ }^{(b)}$ and Peter Ayton ${ }^{(a)}$ \\ (a) University of Leeds \\ ${ }^{(b)}$ Central Queensland University
}

\begin{abstract}
When deciding where to invest, individuals choose mutual funds based on recent past performance, despite standard mandated disclaimers that "past performance does not guarantee future results." Investors would receive better longterm returns by choosing funds with lower fees. We explored the impact of fees and past performance on realistic mutual fund selections across three preregistered repeated choice experiments $(\mathrm{N}=1,600)$, while manipulating the presence of disclaimers between-participants. Participants persistently chased past performance despite the opportunity to learn about the futility of this strategy during sixty repeated decisions with feedback. The standard regulatory-mandated disclaimer did not help most participants, compared to giving no advice at all, and was even counterproductive for participants with low levels of financial literacy. An alternative disclaimer which explicitly highlighted the advantages of fee minimization reliably helped participants. We show how individuals who lack both financial literacy and prior investment experience are the most susceptible to making poor mutual fund choices, and can benefit the most from behavioral interventions such as the new disclaimer tested here. We discuss how these results generalize into real-world investment decisions, and how to design more efficient disclaimers that can be used beyond investment choices.
\end{abstract}

Public significance statement: Even when presented with the standard mandated disclaimer that "past performance does not guarantee future results," individuals tend to choose investments based on recent past performance. This research shows how a new disclaimer is better at changing behavior so that investors disregard past performance and choose funds with low fees instead, which do tend to provide better returns on average.

Keywords: investment decisions; behavioral finance; reinforcement learning; regulatory disclaimers; warning messages; financial literacy

${ }^{1}$ This research was funded by the Think Forward Initiative. A non-refereed report providing an early look at the results from Experiments $1 a$ and 2 was published on the website of the funding agency (www.thinkforwardinitiative.com) entitled "Persistent chasing of past performance when selecting mutual funds." (c) 2021, American Psychological Association. This paper is not the copy of record and may not exactly replicate the final, authoritative version of the article. Please do not copy or cite without authors' permission. The final article will be available, upon publication, via its DOI: 10.1037/xap0000358 


\section{Introduction}

Deciding on how to invest one's money is among the most important decisions that people have to make, with long-lasting impact on their financial health. These decisions are not easy, as financial markets are dynamic, complex and data-rich, and most people lack the adequate financial literacy required to understand them (Hadar et al., 2013). Unsurprisingly, given such complex settings, research in behavioral finance has identified many psychological biases in relation to investment decisions (for reviews, see Barberis \& Thaler, 2003; Shefrin, 2009). As a result, people often make suboptimal investment decisions, and research has shown that individual investors tend to earn poor long-term returns on their investments (Barber \& Odean, 2013). Quite often, this is because of excessive expenditures in fees and other transaction costs (e.g., Barber \& Odean, 2000).

One challenging financial decision that individuals often make is investing in mutual funds. Mutual funds pool together money from many investors to buy a portfolio of stocks and bonds, providing simple solutions to help individual investors to access the financial markets with the added benefits of diversification. According to the Investment Company Institute (2019), an estimated 99.5 million individuals in the United States own mutual funds, investing about half of their retirement wealth in them, as well as relying on them to fund education, healthcare, purchasing a house, or preparing for emergencies. Therefore, poor decisions when choosing mutual funds can be deleterious to an individual's well-being across many domains of life. Choosing which mutual fund to invest in is not an easy process, with almost 10,000 mutual funds available for investors in the US, across different asset classes and objectives.

The complexity of the decision process is amplified by the fact that, because of the efficiency and competitiveness of financial markets, when a specific fund outperforms its peers, it is largely just a matter of good luck (Carhart, 1997; Mercer et al., 2010) and short-lived (Bollen \& Busse, 2005). Extensive research on historical market data has repeatedly confirmed that market prices are unpredictable, following what can be described as a random-walk process (Fama, 1995; Malkiel, 1999). This means that mutual fund managers, who are responsible for selecting the investment strategy of a mutual fund, no matter how skilled or experienced, cannot knowingly buy any specific stocks or bonds which will provide better returns in the future than any other stocks or bonds (Fama, 1970; Malkiel, 2003). Consequently, no individual fund can consistently and reliably beat the 
competition (within the same risk profile). ${ }^{2}$ As the United States Securities and Exchange Commission (SEC) says, "past performance does not guarantee future results."

\section{Previous research on mutual fund selection}

Despite this regulatory warning, and the seemingly random nature of the financial markets, many investors do choose funds that have performed well recently (Sirri \& Tufano, 1998). According to Black (1971), it is difficult for investors to convince themselves that the past history of market price movements do not contain any information that can be used to construct a consistently winning portfolio going forward. Because of such skepticism, some fund managers actively exploit the pastperformance bias, by selectively advertising funds that have performed recently well, by chance (as evidenced by the fact that the advertised funds do not maintain superior performance in the postadvertisement period, see Jain \& Wu, 2000; J. J. Koehler \& Mercer, 2009). Fund managers also incubate multiple new funds to artificially (i.e., randomly) generate some funds with good past performance records, which are later promoted to clients, while the ones which performed badly are discarded (Evans, 2010).

While individual funds cannot outperform the competition in terms of the returns of the stocks and bonds selected, there is one important factor in which funds can consistently be better than its peers: fees. In order to cover their running costs, mutual funds managers charge fees from their client investors, which average $0.55 \%$ of assets per year for equity mutual funds (Investment Company Institute, 2019). This might seem like a low percentage, but it equates to an expenditure of more than US\$100 billion per year in the United States alone. One key differentiating factor in costs between funds is how the individual stocks and bonds are selected by the fund's manager: actively or passively. Active fund managers constantly evaluate the markets for what they believe are the most attractive investment opportunities, trying to predict those which will outperform the market (with limited success, see Malkiel, 1995). For this added service, active funds are more expensive, charging $0.76 \%$ per year on average, with some funds charging upwards of $2 \%$ per year. Passive funds provide a more standardized product which replicates market indices without trying to outperform them, by buying all the stocks and bonds contained in a chosen index (e.g., the 500 constituent stocks of the S\&P 500 index). With this simpler (and more automated) strategy, passive funds can be cheaper,

\footnotetext{
${ }^{2}$ Funds that take more risk, for example, by choosing riskier investments, are expected to provide higher returns (in the long-run and with larger variance) than a fund that takes less risk. This is called the "risk premium" (Siegel, 1992), which compensates investors for higher risk-taking. So while a high-risk fund is expected to beat a lowrisk fund in the long-run, no individual fund within the same risk profile can be expected to consistently beat its competitors, without taking more risk.
} 
charging $0.08 \%$ per year on average, with the first zero-fee index-tracking passive funds introduced by Fidelity Investments in the US in $2018 .^{3}$

There is no evidence that the higher fees of a more expensive fund will be compensated by higher returns (Daniel et al., 1997; Grinblatt \& Titman, 1989). According to Malkiel (1999), a randomly selected portfolio of stocks can be expected to do as well as any professionally selected one (especially after accounting for the additional costs associated with active portfolio management). In fact, random portfolios have won many "competitions" against professional investors (e.g., Atkins \& Sundali, 1997; Liang et al., 1995). Other comparisons show that active funds cannot consistently outperform passive funds in the long-run (Haslem et al., 2008), given that passive funds are cheaper on average. This is not to say that an expensive active fund always performs worse than its peers. Instead, it means that on average, they will perform worse more often than they will perform better, and any periods of better performance are not sustainable over the long-run (Black, 1971). A fund manager who was better than average one year has a lower than $50 \%$ chance of doing better than average the following year (Malkiel, 1999).

Because cheaper funds are not as heavily burdened by the drag of definite (and negative) recurring fees, choosing the lowest-fee fund for any given asset class and risk profile (such as large US stocks) is a proven method to get above-average future performance (Elton et al., 2004; Haslem et al., 2008; Volkman \& Wohar, 1995). However, individuals tend to disregard costs when choosing investments, and end up overpaying for their investments with no added benefits for their extra expenditure (Choi et al., 2010; Fisch, 2010; Houge \& Wellman, 2007). When asked to rate the importance of different fund selection criteria, most investors consider fees to be relatively unimportant (Capon et al., 1996; Fisch \& Wilkinson-Ryan, 2014). It is therefore essential to investigate more about why many investors have not learned the truths about the irrelevance of past performance and the significance of fees in mutual fund selection.

Laboratory studies designed to attempt to understand the past performance bias and nudge investors toward more fee-conscious strategies have found that past performance bias is remarkably robust. Choi et al. (2010) presented a group of educated and financially-literate Harvard staff members with a single-choice portfolio allocation task. Participants were later paid a financial bonus based on their chosen funds' future returns. The choice was between four passive funds, which were all designed to track the returns of large US stocks represented in the S\&P 500 index. These funds were strategically chosen by the experimenters, so that the highest-fee fund had the highest average past performance, creating an unrealistic positive correlation between fees and returns. Index funds

\footnotetext{
${ }^{3}$ The funds are called Fidelity ZERO Total Market Index (Symbol: FZROX), ZERO Large Cap Index (FNILX), and ZERO International Index (FZILX).
} 
attempt to replicate the overall market return, so there is no reason to expect this chance outperformance to persist. Nonetheless, participants' performance on this task showed a strong past performance bias favoring high-fee funds.

Experimental research has attempted to understand the potential drivers of past performance bias. Discrete choice experiments (which ask participants to make a single choice) have confirmed that fees are given much less weight than past returns (Pontari et al., 2009; Wilcox, 2003). Converting percentages into corresponding monetary amounts has been shown to have limited effectiveness (Choi et al., 2010; Newall \& Love, 2015). Other research has found that the current SEC mandated disclaimer did not help participants to minimize mutual fund fees, showing that more strongly-worded statements are needed (Mercer et al., 2010). The most effective alternative statement found thus-far appears to be one emphasizing the benefits of investing in low-fee funds, in comparison to other investors: "Some people invest based on past performance, but funds with low fees have the highest future results" (Newall \& Parker, 2019).

\section{The psychology of past performance}

From a psychological point of view, being asked to disregard past outcomes when making future decisions can be difficult and counter-intuitive (Gureckis \& Love, 2009b; Rakow \& Miler, 2009; Tunney \& Shanks, 2002). This is because past outcomes constitute an important component of decision-making strategies in most domains of life: individuals tend to pick the alternative that has provided the best outcomes in their past choices (Dayan, 2009; Edwards, 1961), and avoid the alternatives with poor past outcomes (Denrell, 2007; Denrell \& March, 2001). This is the basic assumption behind most reinforcement-learning models, which posit that individuals accumulate experience by observing the outcomes associated with past actions, and evaluate this corpus of experience when considering future actions (Dayan \& Niv, 2008; Rescorla \& Wagner, 1972; Sutton \& Barto, 1998).

How far in the past an individual should look when considering their options depends on the environment (Hogarth \& Einhorn, 1992). In static environments, the more information an individual can accumulate, the closer their knowledge will represent the true nature of the alternatives, facilitating the identification of the better choices (Fiedler, 2000; Rakow \& Miler, 2009). However, information search can be costly (in terms of both time and effort), and when given the option to explore environments freely before making a decision, individuals often only gather a few limited samples of information, instead of exploring the environment ad nauseam, before making a decision (Hertwig \& Pleskac, 2010; Plonsky et al., 2015). More information can also ultimately reduce cognitive understanding, given that more data needs to be kept in memory and processed (Fiedler, 2000). 
This preference for smaller samples of information might show a human adaptability to more realistic dynamic environments (or simply boredom) and can even facilitate decision-making by increasing the saliency of the differences between the alternatives (Kareev, 2000). In dynamic environments, the structure of the outcomes can change over time, therefore relying on very old information (i.e., outcomes generated before the most recent structural change) can lead to incorrect decisions, since they are no longer representative of the current environment (Rakow \& Miler, 2009; Plonsky et al., 2015). As a result, if the environment is always changing, it is beneficial to disregard old information and base one's decisions on a smaller subset of the most recent outcomes. This creates a recency effect: the reliance on more recent outcomes, while discounting or completely disregarding old ones (Ashby \& Rakow, 2014; Gureckis \& Love, 2009b; Hertwig et al., 2004). The disadvantage is that small samples can be biased, creating divergences from the true nature of the outcomes, which can lead to biased decisions (Fiedler, 2000).

An extreme example of the recency effect is the win-stay-lose-shift (WSLS) decision heuristic. This is a very simple strategy that does not depend on long-term memory and focuses only on the most recent information (Biele et al., 2009) and does not require any learning (Worthy, Pang, \& Byrne, 2013). Individuals who follow a WSLS strategy stay with their chosen alternative if its most recent outcome "won" in comparison to others, or shift to another alternative if it "lost." While WSLS is a poor strategy in many decision making spaces (Lee et al., 2011; Shanks et al., 2002), it seems to be widely employed (Otto et al., 2011; Worthy, Hawthorne, \& Otto, 2013), probably because of its frugality.

These decision-making strategies can explain the past performance bias observed in mutual fund selection (Choi et al., 2009). It is likely that investors take a perfectly valid decision cue from other environments (past performance), but apply it inefficiently to an environment in which it is not valid (investment decisions). Given the dynamic and complex nature of the financial markets, it would be reasonable to expect that individuals employ strategies aiming to simplify the environment and reduce cognitive load, by focusing only on more recent outcomes (Hills et al., 2013; Payne et al., 1988). Such preference for small samples might explain why individuals seem to invest based only on recent experience, rather than a more comprehensive totality of accumulated experience (Rieskamp, 2006). However, because an expensive fund might randomly outperform others in short spells (Bollen \& Busse, 2005), it might not be possible to observe that cheaper funds outperform their expensive peers based only on small samples. As a result, choosing funds based on recent past performance is a suboptimal strategy. 


\section{Overview of experiments}

The extant research on mutual fund selection suffers from two major limitations, which we address in our current research. First, the majority of research in this area employs single-choice paradigms. Participants are typically shown information about a set of mutual funds, and are asked to make a single selection in which to invest. These single-choice experiments do not allow for participants to learn from their choices. This limitation is relevant, given field evidence that investors learn to invest based on how assets perform over time (Choi et al., 2009). Real investment decisions are similar to repeated decisions with feedback: Individuals act on the feedback they receive from the performance of their investments (Benartzi \& Thaler, 1999). With a repeated-choice decision task we are able to track the decisions over time, and evaluate how individuals integrate past performance information into their decisions.

Second, and not unrelated to the first limitation, single-choice experiments create another problem which potentially undermines ecological validity. Single-choice experiments have often forced a positive relationship between fees and past performance, in order to create a testable tradeoff hypothesis between fee-minimization and performance bias (e.g., Choi et al., 2010; Fisch \& Wilkinson-Ryan, 2014; Mauck \& Salzsieder, 2017; Wilcox, 2003, but see also Pontari et al. 2009, for an exception). Critically, and jeopardizing the generalizability of the findings, this is not a representative design (Dhami et al., 2004). In reality, for mutual funds representing any given asset class, there exists a negative relationship between fees and performance: cheaper funds are better in the long run (Haslem et al., 2008; Volkman \& Wohar, 1995). This negative relationship is not clearly observable in the market due to survivorship biases arising because poorly-performing high-fee funds are frequently closed by mutual fund providers (Brown et al., 1992; Dukes et al., 2006; Evans, 2010). If participants never observe the low-fee fund outperform the high-fee fund, there is an even weaker rationale for choosing them, which might inflate the past performance bias observed in previous research with a forced positive correlation.

Here we present a set of three repeated-choice experiments correcting for these limitations. We asked large and diverse samples of individuals $(N=1,600)$ both with and without prior personal investments in stocks and with a wide range of financial literacy to make 60 consecutive incentivized mutual fund investment decisions choosing between two funds based on historical market data. Our results are also relevant to the whole mutual fund market, exploring patterns of error across both passive and active funds. We introduce random noise, generating within-subjects variation in fund performance as, in real life, each fund can deviate from its benchmark. The random noise also eliminates any short-term positive correlation between fees and past performance, introducing instead a small negative long-term correlation; the low-fee fund outperforms the high-fee fund slightly 
more than $50 \%$ of the time. By presenting a low-fee fund which can outperform the high-fee fund, and by using a repeated-choice task which allows participants to learn from their choices, we will be able to test the robustness of the past performance bias in a more challenging (and realistic) setting. We test the influence of two disclaimers on reducing past performance bias, including a disclaimer which provides directed clues identifying optimal behavior (Fu \& Anderson, 2008; Yechiam et al., 2001). A brief cognitive model comparison explores different ways in which past performance can be used to inform investment decisions (Rieskamp, 2006).

\section{Methods}

In three preregistered experiments, we investigated the extent to which investors use past performance or management fees when choosing between two simulated mutual funds. ${ }^{4}$ Participants were asked to choose between one low-fee and one high-fee fund, repeatedly, for 60 trials. Each trial represented one month of investment based on real historical market returns. Apart from the difference in fees, the returns of the two funds were generated dynamically by the same underlying (but independently implemented) stochastic process: the S\&P 500 index returns perturbed with a trendless random noise component. Because the noise had a mean of zero, both funds had the same expected gross performance (before fees) in the long run, even if they differed every month. Participants were compensated financially according to the returns of the funds they selected.

All three experiments were between-subjects designs, manipulating a disclaimer which was presented (or not) before participants started selecting funds. Experiment 1a had two experimental conditions. In the standard condition, participants saw an industry standard disclaimer used when marketing mutual funds, which said "Past performance does not guarantee future results." In the nodisclaimer condition, participants saw a neutral message instead: "Please click the button below when you are ready to start the task." Experiments $1 \mathrm{~b}$ and 2 repeated the two conditions from Experiment 1a and added one additional experimental condition, the social condition: "Some people invest based on past performance, but funds with low fees have the highest future results," a disclaimer first used in Newall and Parker (2019).

\section{Participants}

A total of 1,600 participants were recruited on-line using Prolific Academic across three experiments. Participation was restricted to United States nationals. We filtered participants according to a pre-screening question captured by Prolific Academic: "Have you ever made

\footnotetext{
${ }^{4}$ The experimental materials, JavaScript code, raw data, and full data analysis scripts in $\mathrm{R}$ can be found online in Open Science Framework (OSF) at https://osf.io/k8us3. The tasks were preregistered at https://osf.io/k8us3/registrations.
} 
investments (either personal or through your employment) in the common stock or shares of a company?" Experiments 1a and 1b captured experienced participants who had answered "yes" to that question while Experiment 2 captured inexperienced participants who had answered "no." Participants were not allowed to participate in multiple experiments. In addition to a fixed amount of US\$2.50 for completing the task, participants were paid a performance bonus, which was based on the accumulated returns of the funds they selected ( $M=U S \$ 4.30, S D=1.68$, range $=[0,11.70]$ ). Nine participants ended with a negative bonus, which was not taken from their fixed payment. The study received ethical approval by the City University London Research Ethics Committee reference ETH1819-0392. ${ }^{5}$

\section{Experiment 1a: Prior investments and index funds}

We recruited 400 participants who had made prior investments in stocks and shares (130 females; age: $M=36.7$ years, $S D=11.6$ years), 200 in each of the two disclaimer conditions (none and standard). No participants were excluded from the analysis.

\section{Experiment 1b: Prior investments and active funds}

We initially recruited 600 participants who had made prior investments in stocks and shares, 200 in each of the three disclaimer conditions (none, standard, and social). As per the preregistered procedure, one participant from the social condition was excluded for completing the task in less than 2 minutes (261 females; age: $M=37.8$ years, $S D=12.0$ years).

\section{Experiment 2: No prior investments and index funds}

We initially recruited 600 participants who had not made prior investments in stocks and shares, 200 in each of the three disclaimer conditions (none, standard, and social). Four data-sets, from two participants, were excluded as each individual completed the task twice, two from the social and two from the standard condition (341 females; age: $M=32.5$ years, $S D=12.6$ years).

\section{Task}

The experiment started with a short introduction to mutual funds, including the fact that they charge management fees, which are paid regardless of performance. Participants were told that they would be asked to choose between two similar mutual funds. They were told that the returns shown were based on actual historical data, and that the two funds were closely related to a broad US-index, the S\&P 500, which was also briefly described. In Experiments 1a and 2, the funds were described as

\footnotetext{
${ }^{5}$ Authors LWC and PA were at City University London when the data was originally collected.
} 
index-tracking funds, which aimed to closely match the S\&P 500 index; in Experiment $1 \mathrm{~b}$, the funds were described as actively managed funds, which aimed to outperform the S\&P 500 index by as much as possible. Full instructions can be found in Appendix C.

After the instructions were read, a disclaimer was shown on screen, the wording of which depended on the experimental condition, as explained above. This was the key manipulation for the task. To increase awareness of the disclaimer, participants were asked to acknowledge that they read the disclaimer by clicking a button before continuing. The disclaimer remained on screen throughout the task (Figure $1 \mathrm{~A})$.

[FIGURE 1 HERE]

Participants had to choose between a low-fee fund and a high-fee fund, 60 times. In Experiments $1 \mathrm{a}$ and 2 , the low-fee and high-fee funds had annual management fees of $0.1 \%$ and $0.7 \%$ respectively; in Experiment $1 \mathrm{~b}$, the fees were $0.5 \%$ and $1.5 \%$ respectively. The lower figures were chosen to be close to the asset-weighted averages, and the higher figures were close to the simple averages, of index equity mutual funds (Experiments $1 \mathrm{a}$ and 2 ) and actively managed mutual funds (Experiment 1b) according to Investment Company Institute (2019, p.120). The management fees for each fund were always on display underneath each fund. All returns shown to participants were net of fees, and this was clearly indicated in the instructions.

Before their first selection, participants were shown a historical 12-month return for each fund (Figure 1A). These returns were calculated using the actual monthly S\&P 500 returns for the 12 -month period from December 2012 to November 2013, plus a random noise component, minus fees, which will be explained below. The accumulated S\&P 500 return for the historical period was $24.90 \%$. Participants were instructed that this historical return would not count towards their accumulated bonus. After participants made their first selection, these historical returns were removed from the screen. This first trial mirrored the extant mutual fund experiment literature (e.g., Choi et al., 2010), where choices are made based upon historical returns; in comparison, the remaining 59 choices were based on experienced returns - which counted towards participants' bonuses.

After each selection, participants were shown the net returns for both funds (full feedback, Figure 1B). The task involved 60 trials, each representing one month of real historical market data. The monthly returns for each fund were calculated dynamically, based on the S\&P 500 returns for the period of 60 months from December 2013 to November 2018. The accumulated S\&P 500 return for the 60 months was $45.04 \%$. For each fund $i$, its monthly return for time $t\left(\operatorname{Ret}_{i}(t)\right)$ was calculated by 
taking the index return for that month $(S P(t))$, adding a noise component $N\left(0, \sigma_{e}\right)$, and deducting the relevant monthly fees $\left(\right.$ Fee $\left._{i}\right)$ :

$$
\operatorname{Ret}_{i}(t)=S P(t)+N\left(0, \sigma_{e}\right)-\text { Fee }_{i}
$$

The noise component was stochastically generated, independently for each fund, from a normal distribution with mean zero and standard deviation of $\sigma_{e}$. Because the mean of the noise component was zero, the only long-term expected difference between the two funds was the difference in fees. This gives an expected advantage to the low-fee fund, mirroring real world mutual fund returns (Carhart, 1997). The standard deviation of the noise $\left(\sigma_{e}\right)$ was the same for both funds within each experiment, but changed according to experiment. They were chosen based on a database compiled by Petajisto $(2013)^{6}$ which calculated the noise of the difference in returns of 2,647 mutual funds from their respective benchmarks (which, in the case of the funds used here, it is clearly identified as the S\&P 500 index.) In Experiments 1a and 2, which described index-tracking funds, $\sigma_{e}$ was $2 \%$ for both funds (per month), which matches the 90 th percentile of index fund noise according to Petajisto (2013). While most index-tracking funds have very low noise relative to their benchmarks, it is not uncommon for poorly managed funds to achieve noise of $1 \%$ per month or higher (see also Frino \& Gallagher, 2002; Frino et al., 2004; Israelsen \& Cogswell, 2007). The 90th percentile for index funds was chosen to generate dispersion in the returns every month - by using the median the noise would not have been variant enough, and the differences in past performance might have been too small to reliably observe any behavioral biases. In Experiment $1 b$, which described actively managed funds, $\sigma_{e}$ was $2.5 \%$ for both funds, which matches the 50th percentile of noise of non-index funds also in Petajisto (2013). Any potential concerns that Experiments 1a and 2 are not representative designs for employing extreme examples of passive funds, can be assuaged by the extent to which convergent results are found in Experiment 1b, which more closely reflects typical actively-managed funds.

Participants were paid a bonus of US\$1 for each $10 \%$ of accumulated bonus, pro-rata. Each month's simulated returns for the fund that the participant had chosen were added to their accumulated bonus, which started at zero. To simplify the task, returns were simply added, not compounded. This is because investors misunderstand exponential compounding (Stango \& Zinman, 2009), especially when there are both positive and negative returns (e.g., an increase of $50 \%$ followed by a decrease of $50 \%$ ), as they underestimate the level of asymmetry in growth processes (Ensthaler et al., 2018), making it harder to track how each additional return contribute to their final position. In addition, as one cannot compound from a starting point of zero, compounding would require the

\footnotetext{
${ }^{6}$ www.petajisto.net/data.html.
} 
temporary loaning to participants of an initial monetary endowment, potentially introducing unnecessary complexity and endowment effects. The amount they earned was similar to realizing any gains or losses after every month, instead of capitalizing the returns. Accumulated performance in percentage and monetary bonus equivalent was always present on screen.

After finishing the fund selection task, participants completed the 13-question financial literacy questionnaire from Fernandes et al. (2014). There was no significant difference in financial literacy scores for participants in Experiments $1 \mathrm{a}$ and $1 \mathrm{~b}$ (Exp1a: $M=10.09, S E=0.13$, Exp1b: $M=9.80$, $S E=0.11 ; t(1592)=1.68, p=.21)$. Perhaps because they had prior personal experience investing in stocks, participants in Experiments $1 \mathrm{a}$ and $1 \mathrm{~b}$ scored significantly higher than participants in Experiment 2, who had never made investments in stocks (Exp2: $M=7.84, S E=0.11$, both pairwise $p s<.001$ against $1 \mathrm{a}$ and $1 b) .{ }^{7}$ On average, the task took 10.26 minutes to complete $(S D=5.53)$.

\section{Results}

The dependent variable analyzed was the selection from the low-fee fund, a binary variable. Higher is better, as selecting more often from the low-fee fund reduced fees and resulted in higher returns. ${ }^{8}$ The aim of the preregistered analysis was to compare the frequency of selection from the low-fee fund according to the different disclaimer messages.

There were four preregistered independent variables: (1) the disclaimer messages; (2) differences in returns between the two funds, calculated as the returns from the low-fee fund minus the returns from the high-fee fund, with positive values meaning that the low-fee fund performed better than the high-fee fund by that amount; (3) financial literacy scores, which varied between 0 and 13, with higher scores indicating higher financial literacy; and (4) trial number, which measures how fund selection behavior changes over time.

Two separate analyses were conducted. Both analyses used generalized linear models with a binomial-logit link function. Our main research interest was in the repeated decisions from experience and if they would be influenced by the differences in returns in each previous trial. This was conducted using a repeated-measures mixed-effects analysis, for trials 2-60. The model contained one withinsubjects repeated measure, which was the trial number, one between-subjects factor, which was the disclaimer message, and two covariates: previous trial return difference, and financial literacy scores. The model included a random slope for trial number and a random intercept for each participant: the random intercept allowed for individual differences in the base level of low-fee fund preferences, and

\footnotetext{
7 Two questions (7 and 11 ) were related to mutual funds. Eliminating these questions from the analyses does not change any of the findings (detailed results in OSF).

${ }^{8}$ There was a positive significant correlation between frequency of selection of the low-fee fund and amount of monetary bonus received $(r(1593)=0.081, p=.001)$.
} 
the random slope accounted for individual differences in the change to low-fee fund selections across trials (equivalent to learning).

Because in the first trial participants did not have any previous trials in which to have experienced returns, but instead were provided with historical returns covering 12 months, we analyzed the first trial separately. This replicates previous research in which subjects are asked to make a single decision based on historical past returns. The between-subjects factor was the disclaimer, with two covariates: the 12-month historical difference in returns and financial literacy scores. Only the main effects and first order interactions were included in both models, which were analyzed using ANOVAs for the categorical disclaimers and regression coefficients for the continuous independent variables.

\section{Changes from preregistered analyses}

We originally preregistered all the results to be extracted from ANOVA tables, including the coefficients of the continuous variables which would be calculated using estimated marginal means. We subsequently found it more helpful to present the coefficients and results directly from the underlying regressions (upon which the ANOVAs were to be based), especially for the continuous independent variables (i.e., trial number, difference in returns, and financial literacy scores), as coefficients can show direction and magnitude. In order to facilitate the presentation and interpretation of the regression coefficients, two changes from the preregistered analyses had to be made. First, a treatment contrast was used for comparing the differences between disclaimer messages, instead of the proposed Helmert contrast. This approach provides a comparison between the two different messages against the no-disclaimer condition as a control. Second, the three continuous variables were mean-centered, by subtracting the mean of each variable from each observation. Mean-centering converts all the coefficients to those of an individual with mean financial literacy scores (instead of a score equal to zero, which would not be as useful), when the difference in returns are zero, and at the middle point of the task (trial 31, instead of trial zero, which did not exist). This transformation is particularly useful when interpreting interactions. We still present the ANOVA results for the categorical variable (disclaimer messages) in the main manuscript, and the full ANOVA table is in Table A1 in Appendix A. The changes to the contrast and the mean-centering of variables do not significantly change results obtained from ANOVA tables, and the use of regression tables instead of ANOVAs do not alter any of the findings or conclusions presented here.

\section{Past performance bias}

At every trial, across all three experiments, we observe past performance bias, with participants selecting more often the fund that had the highest returns at each previous trial (Table 
1(B): Difference in returns). This effect was also observed in the first trial with participants preferring the fund with the highest 12-month historical past performance (Table 1(A): Difference in returns). The slope coefficients for the differences in returns in the regression table are the change in log-odds of the probability of selecting the low-fee fund for changes in the difference in past returns between the two funds: a positive slope represents past performance bias, with an increase in selections of the low-fee fund when it outperforms the high-fee fund. The probability of selecting the winning fund was also influenced by the magnitude of the difference in returns: when a fund outperformed the other by a larger amount, the probability of it being selected in the trial increased (Figure 2).

[FIGURE 2 HERE]

There was a significant and negative interaction between past performance and financial literacy in the repeated trials of Experiments 1a and 1b but not in Experiment 2 (Table 1(B): Difference $\times$ Fin. Lit.). Increases in financial literacy were associated with a reduction in past performance bias. Participants with higher financial literacy performed better in the task, with lower performance bias. For participants with the highest financial literacy scores (11 to 13), the past performance bias was nearly eliminated, with almost flat curves, as can be seen in Figure 2 . This was only observed in the first two experiments in which participants had prior personal experience with stock markets, but not in the last experiment with less experienced participants. In Experiment 2, financial literacy levels did not change past performance bias. As we will discuss later, we believe that this is because both prior experience of financial markets and high financial literacy are crucial to reduce past performance bias - which was the case for participants in Experiments 1a and 1b but not in Experiment 2. The interaction between past performance and financial literacy was not significant in the first trial in any of the experiments (Table $1(A)$ : Difference $\times$ Fin. Lit.), suggesting that experienced participants were better able to learn over time through repeated experience and improve their choices.

\section{Influence of disclaimer}

There was no overall main effect of disclaimer in Experiment 1a, in the repeated trials, with no difference in selections between no disclaimer and the standard disclaimer (Exp.1a: $\chi^{2}(1)=0.50$, $p=.48$ ). Participants chose the low-fee fund as frequently with the standard disclaimer as with no disclaimer (Exp. 1a: none=86.4\%, standard=83.5\%). This lack of significant differences between no disclaimer and the standard disclaimer was also observed in Experiments $1 \mathrm{~b}$ and 2 (Table 1: Disclaimer=standard), showing that the standard disclaimer does not help improve fund selection in relation to no disclaimer (Exp. 1b: none $=79.2 \%$, standard $=78.4 \%$; Exp. 2: none $=65.9 \%$, standard $=66.3 \%$ ). The same lack of effect was observed in the first trial of Experiment 1a (Exp.1a: 
$\chi^{2}(1)=0.79, p=.38$ ). The regression results in Table 1 (Disclaimer=standard) show a lack of significant changes to low-fee fund selections with the standard disclaimer in comparison to the control, across all experiments and all trials.

There was however a significant main effect of disclaimer in the repeated trials of Experiments $1 \mathrm{~b}$ and 2, due to the addition of the social disclaimer (Exp.1b: $\chi^{2}(2)=21.15, p<.001 ; \operatorname{Exp} .2: \chi^{2}(2)=79.83$, $p<.001)$. The social disclaimer helped participants choose the low-fee fund significantly more often than no disclaimer, across both experiments with a social disclaimer (Exp1b: social=91.0\%; Exp2: social=89.4\%). The same effects were observed in the first trial for Experiments $1 \mathrm{~b}$ and 2 (Exp.1b: $\left.\chi^{2}(2)=26.57, p<.001 ; \operatorname{Exp} .2: \chi^{2}(2)=21.48, p<.001\right)$.

In the repeated trials across all three experiments, the interaction between disclaimer and previous trial difference was significant $\left(\right.$ Exp.1a: $\chi^{2}(1)=17.43, p<.001$; Exp.1b: $\chi^{2}(2)=14.69, p=.001$; Exp.2: $\left.\chi^{2}(2)=21.19, p<.001\right)$. In Experiments 1 a and 2, this was due to the flatter slope coefficient for previous trial difference with both disclaimers, indicating that past performance bias was lower when there was a disclaimer and the funds were passive with lower noise (Table 1: Disclaimer=standard $x$ Difference and Disclaimer=social $\times$ Difference). On average, the presence of both disclaimers reduced past performance bias in relation to no disclaimer, flattening the curve, but did not completely eliminate it. However, we observed a different effect in Experiment 1b, in which the standard disclaimer increased the past performance bias for repeated trials from experienced investors choosing between actively managed funds (Table 1(B), Exp.1b: Disclaimer=standard $\times$ Difference). This is the opposite of the desired effect for the disclaimer. This reversal was not observed in the first trial (Table 1(A), Exp.1b: Disclaimer=standard $\times$ Difference), which indicates that perhaps participants learned this behavior as the task progressed, by believing that any outperformance of a fund in one trial would repeat in the next trial, perhaps due to the active fund manager's skill.

The interaction between disclaimer and financial literacy was significant in the repeated trials for Experiments 1a and 2, but not significant for Experiment 1b (Exp.1a: $\chi^{2}(1)=6.79, p=.009$; Exp.1b: $\chi^{2}(2)=3.88, p=.144$; Exp.2: $\left.\chi^{2}(2)=10.68, p=.005\right)$. The slope coefficient is the change to the logs-odds for the probability of selecting the low-fee fund for every additional correct answer in the financial literacy score. In the repeated trials of Experiments $1 \mathrm{~b}$ and 2, we observed a significant increase in the slope for financial literacy with the social disclaimer (Table 1(B): Discl=social $\times$ Fin. Lit.). Participants with high financial literacy reacted to the social disclaimer more, choosing more often from the low-fee fund. This trend was also observed in Experiment 1a, but with the standard disclaimer (Table 1(B): Discl=standard $\times$ Fin. Lit.). This interaction was not significant in the first trial of any of the experiments. It seems that the disclaimers had a different effect according to the level of financial literacy, creating a wider differentiation between participants than when there was no disclaimer. The side effect of 
this wider differentiation is that while it leads to participants with higher financial literacy choosing the low-fee fund more often, it also leads to participants with lower financial literacy choosing the low-fee fund less often. In the case of the standard disclaimer, which did not cause an overall increase in the selection of the low-fee fund, it was associated with an adverse effect for low financial literacy participants, causing them to select the high-fee fund more frequently, and was only beneficial to participants with prior experience and high financial literacy, as can be seen in Figure 2. In contrast, the social disclaimer was associated with higher selections of the low-fee fund for all participants (but more so for participants with higher financial literacy).

\section{[TABLE 1 HERE]}

\section{Learning from experience}

There was a significant effect of trial number, in all three experiments, indicating that participants were selecting the low-fee fund more often as the task progressed (Table 1: Trial number). The slope coefficient is the change to log-odds of the probability of selecting the low-fee fund for each 100 trials. However, the small coefficients translate to a relatively small (albeit statistically significant) increase in selections of the low-fee fund of around 5-10 percentage points over the 60 trials of the task. Overall there is some indication of learning, but it appears to have been limited, and did not completely eliminate past performance bias over the course of the task. We explore how learning might have occurred in more depth in the next section using cognitive modelling.

\section{Cognitive modelling}

In the experimental results presented above, the fund selected at each trial was influenced by the past performance from the previous trial. If past performance is influencing mutual fund selections, then a cognitive model which also relies on past performance should be able to correctly predict each participant's behavior. By using competing models which accumulate and integrate information in different ways, we can further evaluate how learning processes and past performance influence mutual fund choices (Rieskamp, 2006). This additional analysis was not pre-registered, and was conducted after the statistical analyses.

We tested two competing models which rely on past information, which have been compared before to evaluate repeated decision-making between risky gambles with gains and losses (Worthy, Hawthorne, \& Otto, 2013; Worthy, Pang, \& Byrne, 2013). Each model considered a different horizon of past information: the reinforcement-learning $(\mathrm{RL})$ model combines long-term past information from all previous trials, while the win-stay-lose-shift (WSLS) model only considers short-term information 
from the most recent previous trial. We also tested a low-fee model, which always selected the lowfee fund, which is the optimal behavior and the ultimate objective of the disclaimers tested in our experiments. All models were compared to a base naive random model, which assumed random selections between the two funds, and describes the simplest and most basic behavior possible. The models are described in more detail in Appendix B.

\section{Reinforcement learning model}

Reinforcement learning models assume that individuals calculate and store an expectancy value for each available alternative (Sutton \& Barto, 1998). These expectancies summarize all the information observed so far, and are updated after every trial, using a learning rule. We have chosen the expectancy-valence (EV) model with its delta-learning rule, which has been shown to explain behavior well in many different types of risky decision-making studies (Gureckis \& Love, 2009b; Speekenbrink \& Konstantinidis, 2015; Yechiam \& Rakow, 2012). Expectancies are updated by a modelfitted proportion of the prediction error, which is calculated as the difference between the latest observed outcome and the previous expectancy. A ratio choice rule is then used to determine the probabilities of choosing each alternative according to the relative values of their expectancies (Yechiam \& Busemeyer, 2005). If one alternative has a much higher expectancy, it will be chosen with higher probability. If two alternatives have similar expectancies, then they are chosen with equal probability.

\section{Win-stay-lose-shift}

In contrast to RL models, which require memory and cognitive effort to calculate expected outcomes after every trial, the WSLS model is a much simpler heuristic-based model, which requires little cognitive effort and does not involve learning or memory (Worthy \& Maddox, 2012). The WSLS model assumes that individuals only look at the difference in values of the most recent previous trial. It simply states that individuals stay with their chosen option if it "wins," or shift away to another option if it "loses" (Worthy, Hawthorne, \& Otto, 2013). At every trial, the model starts by comparing the performance of the two alternatives in the previous trial. If the previously chosen alternative is better than the unchosen one, then the model chooses the same alternative with a model-fitted probability of staying. If the previously chosen alternative was worse than the unchosen one, then the model chooses the unchosen alternative with a model-fitted probability of shifting.

\section{The random and low-fee models}

The two other models do not take into account any observed past performance information to inform their selections. They simply repeat the same behavior across all trials, regardless of any 
feedback received. The naive random model assumes no pre-existing knowledge of financial markets, and simply chooses options at random, with each fund having a probability of $50 \%$ of being selected at every trial. The low-fee model expects that participants have some pre-existing knowledge of financial markets (or have been informed of it, for example, by a disclaimer), namely that the low-fee fund is always the best option to choose, and chooses the low-fee fund at every trial with probability $100 \%$.

\section{Modelling results}

All models were evaluated for their ability to predict the next choice ahead for each participant at every trial. The two competing models were fitted against participants' data at individual level, to find the optimal value for the free parameters for each model for each participant. The models were fed the actual choices and past performance information observed for each participant. The modelling was done only on trials 2 to 60 , to match the statistical analyses in the previous section. The model closer to the actual behavior for each participant was declared the best fitting model for that participant (more details in Appendix B).

Model fitting results are in Table 2, which shows how many participants in each experimental condition had their behavior best fit by each model. Behavior from $46 \%$ of participants was fit better by the WSLS model, indicating that participants mostly followed a simple rule of choosing the winning fund from each previous trial. The RL model provided the best fit to $18 \%$ of participants. These participants employed a more sensible strategy of choosing the funds based on a longer period of past performance. This is a better strategy in terms of identifying the low-fee fund as the best option, as it reduces the short-term noise associated with the WSLS model. After enough observations, the RL model would predict choosing the low-fee fund more often given its low cost advantage.

\section{[TABLE 2 HERE]}

The low-fee model was the best fit for $23 \%$ of participants. These participants showed the best behavior for the task, which was selecting the low-fee fund all trials. However, this was behavior not distributed evenly across the experimental conditions. The low-fee fund fitted more participants in the social disclaimer condition (31\%) than in the no disclaimer (20\%) or the standard disclaimer conditions (22\%), with a significant difference according to a contingency table $\left(\chi^{2}(2)=18.11, p<.001\right)$. As observed in the statistical analyses, the social disclaimer helped more participants achieve the optimal behavior of choosing the low-fee fund most of the time. Those participants whose best fitting model was the low-fee model also had higher financial literacy than any of the other models (10.54 compared to $8.34-8.88$, all pairwise $p s<.001)$. 
The best fitting model, the WSLS model, confirms that participants persistently chased past performance from the most recent previous trial, instead of learning over time that the low-fee fund was better by accumulating performance over many trials, which would eventually reduce random noise. A similar preference for relying on short-term past performance in mutual fund decisions was observed by Rieskamp (2006). One of the reasons why individuals might prefer the WSLS strategy is because it reduces cognitive and working memory load, even if it leads to suboptimal behavior. This is another reason why a simple cue or instruction, such as the social disclaimer employed here, is important to shift behavior towards optimality in such a complex dynamic environment (Yechiam et al., 2001). However, any such instruction would have to fight against the individual's natural tendency to react to past performance.

\section{Discussion}

The present results showed a number of consistent patterns between past performance and fee minimization in realistic mutual fund choices, across three experiments covering index and active mutual funds in a diverse pool of participants. We observed a past performance bias in the first trial, replicating previous findings using static accumulated historical past returns (Choi et al., 2010; Fisch \& Wilkinson-Ryan, 2014; Mauck \& Salzsieder, 2017). In the subsequent repeated-choice trials with dynamically generated returns, participants continued to chase past performance, frequently switching from fund to fund according to the winning fund in the previous trial. Moreover, across three experiments, the standard disclaimer "Past performance does not guarantee future results" failed to help participants to minimize fees, replicating the findings in Mercer et al. (2010). An alternative social disclaimer directly highlighting the advantages of fee minimization (from Newall \& Parker, 2019) performed better, improving performance. These are key findings from the single-choice mutual fund selection literature which replicate with a repeated-choice design, despite participants having the opportunity to learn that chasing past performance is a futile strategy for reward maximization.

\section{Learning in noisy environments}

The dynamic repeated-choice design employed here allowed us to better explore novel mutual fund choice relationships and how learning occurs in noisy environments. The tendency to chase past performance somewhat lessened over the course of the task, as participants gradually learned to correctly minimize fees more often, although the detrimental past performance bias was not completely eliminated and was still present throughout the task. The magnitude by which one fund outperformed the other was a factor in determining the likelihood of that fund being selected: small differences in fund returns did not influence selections as strongly as large differences. Our 
dynamic paradigm with stochastically generated returns also circumvented the previous experimental limitation of high-fee funds always performing better (which is also ecologically invalid, since on average the opposite is true); in our task, the high-fee fund only outperformed the low-fee fund around half of the time (net of fees), within-participants. Even though the same participants saw the funds randomly outperform each other from trial to trial, participants still chased past performance, without seemingly being able to identify the random-walk nature of returns.

Our task employed randomly generated noise, which resulted in the high-fee fund outperforming the low-fee fund by large margins for some small number of participants, and this might have led them to believe that the winning fund was the better choice. This is the nature of stochastic noise and finite samples, and might also happen in real life, when one particular fund outperforms the competition during short periods of time, as a result of random luck (Bollen \& Busse, 2005). However, for the vast majority of participants, each fund outperformed the other roughly half of the time, which should be a realistic representation of any two randomly chosen funds.

Participants might not have fully learned that chasing past performance was an inefficient strategy and that the low-fee fund was better, even after many repeated trials, because of poor signalto-noise ratios. In noisy environments, learning can be severely impaired (e.g., Ratcliff \& Smith, 2010). This is because noise obscures the signal and increases uncertainty ("noise is a curse," Gureckis \& Love, 2009a). When noise is high, it can be more easily misinterpreted as part of the signal: individuals try to explain the noise as being part of the signal (Tversky \& Kahneman, 1971). This belief is also shown by individuals incorrectly incorporating noise into their forecasts when predicting trends in noisy environments (Harvey, 1995). They believe that a noisy forecast is more representative of the data from which it was generated. However, given the stochastic unpredictable nature of noise, any attempts to reproduce it would only lead to worse forecasts. Even when making one single forecast, which is what our participants needed to do, the quality of any single prediction deteriorates in noisier environments (Harvey et al., 1997).

The observed behavior of chasing of past performance might be a reflection of the general tendency that individuals have to identify patterns in data, even when there are none, resulting in a phenomenal sensitivity to patterns resulting from uninformative random noise (Gaissmaier \& Schooler, 2008; Plonsky \& Erev, 2017; Yu \& Cohen, 2009). By incorporating noise as part of the signal, individuals might be seduced by spurious patterns, believing that these can be exploited for their benefit. For example, investors might (incorrectly) believe that the funds that performed well recently employ better investment strategies, allowing them to continue to outperform their peers in the future. 
For risky financial assets, random fluctuations in price (noise) are often much greater than the long-term trend (signal). For example, the S\&P 500 market index during the period utilized in our task had an average monthly return of $0.75 \%$ with a standard deviation of $2.88 \%$. The signal-to-noise ratio is further deteriorated when trying to identify the difference in management fees of two funds within the same asset class, which is an even smaller signal (in our task, this difference was $0.05 \%$ and $0.08 \%$ per month for the passive and active scenarios respectively). Given that differences in fees are much smaller than the difference in variance between funds, it can be particularly difficult to isolate the signal (that the low-fee fund is the better choice) from the random noise, especially with few observations (i.e., in the short-term).

Cognitive modelling confirmed the statistical findings that individuals chase past performance after every trial. It showed that a heuristic WSLS model which decides solely on the basis of performance from the most recent previous trial explained behavior better than an RL model deciding based on all past available performance. A clear implication of this is that participants are choosing based mostly on short-term performance, and are more likely to be influenced by random noise. If individuals were selecting based on a longer horizon of past information looking further into the past, the noise would be reduced in relation to the signal, making it easier to observe that the low-fee fund outperformed the high-fee one.

Identifying that the low-fee fund is the optimal choice is therefore not trivial, and in fact requires much more data than an average investor is likely to be able to access. Because most investors lack the ability to observe for themselves that low-cost funds are the optimal strategy in the long-run, it is important to properly inform investors of the ideal course of action to take. This is the aim of the social disclaimer presented here, which improved observed behavior as intended. The cognitive modelling analysis also confirmed that the social disclaimer led to an increase in participants selecting mostly from the low-fee fund, and in particular those with higher financial literacy.

\section{Prior experience and financial literacy as moderators}

The chasing of past performance was moderated by an interaction of two individual difference variables: participants' prior experience with financial markets; and financial literacy. In the first trial, all participants chased past performance, regardless of financial experience or financial literacy. In subsequent trials, participants who had both previous financial experience and financial literacy showed a greater reduction in chasing of past performance. The combination of both factors appeared to be crucial: the improvement was not as pronounced for participants who had only experience or high financial literacy alone - both experience and knowledge were required. This is compatible with traditional theories of skill acquisition which propose that high performance in complex tasks can be 
achieved via the combination of declarative learning (which can be measured by literacy tests) with procedural experience (Anderson, 1982).

In fact, there was a detrimental effect of financial experience without financial literacy, in the way that the disclaimers influenced behavior. For participants who had prior experience and high financial literacy, both disclaimers were able to flatten the relationship between past performance and selections of the low-fee fund. In these cases, participants selected the low-fee fund almost exclusively. For participants with no prior experience, however, the standard disclaimer was not as effective, while the social disclaimer was still effective in shifting individuals towards the low-fee fund.

The standard disclaimer had a perverse effect on experienced participants with low financial literacy, causing them to select more frequently from the more expensive fund. The standard disclaimer tells investors that past performance should not be taken into account when choosing funds but does not provide an alternative selection strategy. It is possible that investors with low financial literacy misunderstand the true negative relationship between fees and performance, as it is not uncommon for consumers to use high price as a proxy for quality (Rao, 2005). It seems that the standard disclaimer hurts in particular those individuals that are not as well-prepared to deal with investments; participants with low financial literacy were more susceptible to unnecessary overspending on fees.

While we measured financial literacy as a moderator of the behavior observed here, Fernandes et al. (2014) argue that directly increasing financial literacy does not lead to better financial decisions. Instead, measurements of more general statistical numeracy have been proposed as the underlying drivers of financial behavior, such as the Berlin Numeracy Test (Estrada-Mejia et al., 2016; Ghazal et al., 2014). There is, as expected, a high correlation between financial literacy and general numeracy, mostly because the answer to some finance-related questions have numerical reasoning components (Soll et al., 2013). For example, statistical numeracy alone should be enough to understand that a $50 \%$ increase and a subsequent $50 \%$ decrease in stock prices result in negative overall results, without the need to understand the intricacies of the stock markets. Asking individuals to interpret these types of statements ("x\% increase followed by $x \%$ decrease"), Newall (2016) has found that indeed numeracy can be a better predictor of understanding price movements than financial literacy. However, we would argue that, for mutual fund selections (or stock selections in general), statistical numeracy should help but would not suffice without financial literacy. This is because those who are financially literate are more likely to understand the counter-intuitive lack of relationship between past and future returns in financial markets, which cannot be explained by numerical reasoning alone. This hypothesis remains to be tested experimentally. 


\section{Real-world investment decisions}

Like previous mutual fund research, the present design simplified some aspects of real-world investing (Choi et al., 2010), which caveats the external validity of our findings. Participants actively chased the best performing fund, as switching between them was costless. Although mutual fund switching is seemingly costless in some retirement plans, such as the US's Thrift Savings Plan, or the UK's USS Pensions, fund switching is not frictionless and inevitably costs time and money, in terms of commissions, entry or exit fees, taxation, and administrative expenses. These switching costs may encourage investors to switch funds in real life less often than it was observed in our task. However, Barber et al. (2005) report an actual annual mutual fund turnover of $70 \%$, which is still far higher than an optimal buy-and-hold strategy.

In our experiments, participants were exposed to repeated trials representing sixty months of returns, but completed the task in a much shorter space of time - actual re-investment decisions will span longer periods of times and not be made in quick succession. At every trial, participants were required to make a forced investment choice, without the possibility of keeping their money uninvested (i.e., not investing in either fund). Given the random nature of market price movements, being able to divest is not beneficial to overall performance, as investors cannot reliably determine when an asset price is going down in order to avoid losses. As a result, choosing the low-fee fund would remain the behavior that maximizes expected rewards in a task which allows being uninvested. Research has shown that given the option to divest from the market, individuals actually tend to sell winners early and hang on to losers for too long, further amplifying their losses (the "disposition effect," Shefrin \& Statman, 1985). The disposition effect seems to be reduced, but not completely eliminated, with more sophisticated investors (Dhar \& Zhu, 2006; Shapira \& Venezia, 2001). It is likely that allowing for divestments would magnify the influence of financial experience and financial literacy observed in our task. Another possibility that was not tested in our task was that of inertia through inaction. With real-life investments, individuals can choose to leave their investments untouched over many periods, without being constantly prompted to buy or sell any assets. Inaction inertia in financial decisions reduces trading (Tykocinski et al., 1995, 2004) and is likely to limit chasing behavior. Future research should explore this hypothesis.

However, while the limitations above are valid in relation to more traditional ways in which investments are accessed, they might no longer apply, and in fact our paradigm might even more closely match new emerging ways of investing: A new breed of smartphone-based investment platforms are substantially changing the way that individuals make investments (Stewart, 2020). First, these platforms often offer low minimum investments, easy convenient access and costless trading, reducing many of the barriers that would otherwise limit excessive trading described above. Second, 
they often provide users with prompts and notifications to entice frequent portfolio checking and further trading, reducing inertia through inaction (Zweig, 2020). Furthermore, there appears to be a trend towards the "gamblification" of trading, with the aim of transforming it into an addictive activity similar to gambling (Mosenhauer et al., 2021). The influence of social media, bringing individuals who acquire large gains from random lucky investments into the spotlight, while those with similar strategies but who incur losses not being as well publicized, might lead to investors mimicking inefficient behavior. Such social influences can be in direct conflict with the social disclaimer tested here and compromise its efficacy for nudging behavior in the right direction.

With regards to financial rewards, in our experiments selecting the low-fee fund would impart relatively small absolute monetary advantages, with the experiments simulating a US\$10 initial investment compared to the median amount invested in a mutual fund of US\$37,500 in the US (Investment Company Institute, 2019), despite a non-negligible advantage in earnings (7\% in Experiments $1 \mathrm{a}$ and 2 and $13 \%$ in Experiment $1 \mathrm{~b}$ ). Because the task was completed relatively quickly in around 10 minutes, the average pro-rata payment was respectable at approximately US\$40/hour, with those who exclusively selected the low-fee fund receiving an extra US\$2-3/hour than those who never did. Nonetheless, despite much higher financial incentives in Choi et al. (2010), participants still failed to minimize fees, and studies of mutual fund flows have confirmed that laboratory studies of fund selection replicate in the field (Barber et al., 2005; Sirri \& Tufano, 1998).

Another simplification we employed is that in the real markets individuals have to choose between a myriad of different fund across different asset classes, with a much wider range of information provided to investors, creating a much more complex decision environment. Research has shown how increasing environmental complexity can lead to an even greater use of heuristics such as simplification strategies to reduce the amount of information and help facilitate decisionmaking (Payne, 1976; Payne et al., 1988). If individuals are employing simplification strategies in our streamlined laboratory task (such as relying on recent past performance), then it is even more likely that they will need to adopt simple strategies and discard information when facing the complexities of the real markets. The ability to identify the best alternative should deteriorate in more complex tasks, as complexity increases how much individuals disregard warnings and disclaimers (Weiss-Cohen et al., 2018). Furthermore, we would expect the contribution of experience and literacy to be amplified: those individuals who know that past performance is a poor indicator should not be affected as much, but those who do not understand this are even more likely to rely on past performance. We believe that in complex environments the impact of more efficient disclaimers will be even greater, such as the social disclaimer used here. 


\section{Designing more efficient disclaimers}

Because of the high noise, weak signal, and counter-intuitive relationships between short and long-term goals, investing in mutual fund is a very difficult decision. Providing decision cues have been shown to improve behavior in similarly difficult-to-learn tasks with high noise and short-term benefits in conflict with long-term goals (Gureckis \& Love, 2009b). However, using behavioral and computational analyses, we observed that the standard disclaimer does not reduce the inefficient chasing of past performance, despite specifically stating that "past performance does not guarantee future returns."

We believe that the standard disclaimer does not help behavior because it attempts to eliminate past performance as a decision cue, but it does not provide an alternative cue to guide behavior. Simply verbalizing characteristics of a complex system, as the traditional disclaimer does, does not seem to help improve performance (Brehmer \& Kuylenstierna, 1978). Instead, guided instructions and external cues, which identify winning strategies, are needed to help shape behavior in complex environments with misleading local maxima (Fu \& Anderson, 2008; Yechiam et al., 2001). Exploring probability matching in sequential choices, D. J. Koehler and James (2010) suggest that a simpler strategy similar to chasing past performance comes more readily to mind, while the alternative maximizing strategy does not; however, once the superior strategy is brought to mind, more participants subsequently engage in maximizing. This was the aim of the social disclaimer.

Another reason might be that the standard disclaimer fails to break the perceived subjective relationship between past and future performance. Stating that past performance does not guarantee future returns does not completely dissociate the two, because of the perceived vagueness of verbal statistical phrases (Wallsten et al., 1986). Subjective perceptions of probabilistic relationships are typically less extreme than intended, especially when provided verbally instead of numerically (Budescu et al., 2009; Fillenbaum et al., 1991). Individuals might perhaps believe that there is a (potentially still strong) relationship, but it is stochastic, instead of deterministic. The allure of identifying a recurring pattern within randomness is likely to be too great to be dispelled by a simple disclaimer stating that there are no patterns (D. J. Koehler \& James, 2010; Shanks et al., 2002). Any suspicion of a pattern in high noise might be perceived as potential signals of non-randomness in price movements (Kahneman \& Tversky, 1972; Lopes, 1982), leading individuals to more easily dismiss the standard disclaimer of no auto-correlation. In addition, direct personal experience can easily overcome implausible verbally described information, such as warnings, instructions, or cues (WeissCohen et al., 2016). This is because experience is more personal, visceral, and intuitive, while verbal descriptions are more cognitively demanding to process and understand (Lejarraga, 2010). An efficient 
disclaimer aiming to influence behavior should reduce complexity, avoid ambiguity, and provide clear and easy-to-follow instructions (Argo \& Main, 2004).

As a replacement to the traditional disclaimer, we employed instead a social disclaimer, which succeeds in reducing the chasing of past performance, and shifting investors towards the low-fee fund. We believe the social disclaimer influences behavior because it provides a clear, direct, and plausible guide as to how to make investment choices ("funds with low fees have the highest future results"). The social disclaimer specifically highlights low-fees as the optimal choice criterion in lieu of past performance. The social disclaimer also engages social nudging via social comparison and social norming (Osman et al., 2020). Neuroimaging research has shown that investors prefer to correlate their behaviors with the actions of others (Lohrenz et al., 2013), and that such social nudging can increase the subjective value of choices selected by others (Chung et al., 2015). By using a social comparison nudge, we might have provided the necessary differentiating factor that gives the low-fee fund the advantage it needs to be selected in an environment which is otherwise too noisy to allow for easy identification of the optimal choice.

While the social disclaimer's link between fees and future performance was true in this task given that both funds invested in the same assets, caution should be applied to the design of warning labels for funds spanning across different asset classes. The social disclaimer tested here is one example of how the advice currently given to investors could be improved, especially given the complex and counter-intuitive nuances of the financial markets. Future research should continue to explore rival disclaimers that might be even better, as well as alternative financial behavior change interventions (Chin \& de Bruin, 2019; Sims et al., 2020). As Fischhoff (1998) stated, "one should no more release an untested communication than an untested drug" (p. 70). 


\section{References}

Anderson, J. R. (1982). Acquisition of cognitive skill. Psychological Review, 89(4), 369-406. doi: 10.1016/B978-1-4832-1446-7.50032-7

Argo, J. J., \& Main, K. J. (2004). Meta-analyses of the effectiveness of warning labels. Journal of Public Policy \& Marketing, 23(2), 193-208. doi: 10.1509/jppm.23.2.193.51400

Ashby, N. J., \& Rakow, T. (2014). Forgetting the past: Individual differences in recency in subjective valuations from experience. Journal of Experimental Psychology: Learning Memory and Cognition, 4O(4), 1153-1162. doi: 10.1037/a0036352

Atkins, A. B., \& Sundali, J. A. (1997). Portfolio managers versus the darts: Evidence from the Wall Street Journal's Dartboard Column. Applied Economics Letters, 4(10), 635-637. doi: $10.1080 / 758533290$

Barber, B. M., \& Odean, T. (2000). Trading is hazardous to your wealth: The common stock investment performance of individual investors. The Journal of Finance, 55(2), 773-806.

Barber, B. M., \& Odean, T. (2013). The behavior of individual investors. In Handbook of the economics of finance (Vol. 2, pp. 1533-1570). Elsevier B.V. doi: 10.1016/B978-0-44-459406-8.00022-6

Barber, B. M., Odean, T., \& Zheng, L. (2005). Out of sight, out of mind: The effects of expenses on mutual fund flows. The Journal of Business, 78(6), 2095-2120. doi: 10.1086/497042

Barberis, N. C., \& Thaler, R. H. (2003). A survey of behavioral finance. In G. Constantinides, M. Harris, \& R. Stulz (Eds.), Handbook of the economics of finance (pp. 1053-1123). Amsterdam: Elsevier Science B.V. doi: 10.2139/ssrn.327880

Benartzi, S., \& Thaler, R. H. (1999). Risk aversion or myopia? Choices in repeated gambles and retirement investments. Management Science, 45(3), 364-381. doi: 10.1287/mnsc.45.3.364

Biele, G., Erev, I., \& Ert, E. (2009). Learning, risk attitude and hot stoves in restless bandit problems. Journal of Mathematical Psychology, 53, 155-167. doi: 10.1016/j.jmp.2008.05.006

Black, F. (1971). Implications of the random walk hypothesis for portfolio management. Financial Analysts Journal, 27(2), 16-22. doi: 10.2469/faj.v27.n2.16

Bollen, N. P., \& Busse, J. A. (2005). Short-term persistence in mutual fund performance. Review of Financial Studies, 18(2), 569-597. doi: 10.1093/rfs/hhi007

Brehmer, B., \& Kuylenstierna, J. (1978). Task information and performance in probabilistic inference tasks. Organizational Behavior and Human Performance, 22(3), 445-464. doi: 10.1016/00305073(78)90027-2

Brown, S. J., Goetzmann, W., Ibbotson, R. G., \& Ross, S. A. (1992). Survivorship bias in performance studies. Review of Financial Studies, 5(4), 553-580. doi: 10.1093/rfs/5.4.553 
Budescu, D. V., Broomell, S., \& Por, H. H. (2009). Improving communication of uncertainty in the reports of the intergovernmental panel on climate change. Psychological Science, 20(3), 299308. doi: 10.1111/j.1467-9280.2009.02284.x

Capon, N., Fitzsimons, G. J., \& Prince, R. A. (1996). An individual level analysis of the mutual fund investment decision. Journal of Financial Services Research, 10, 59-82. doi: 10.1007/BF00120146

Carhart, M. M. (1997). On persistence in mutual fund performance. The Journal of Finance, 52(1), 5782. doi: $10.2307 / 2329556$

Chin, A., \& de Bruin, W. B. (2019). Helping consumers to evaluate annual percentage rates (APR) on credit cards. Journal of Experimental Psychology: Applied, 25(1), 77-87. doi: 10.1037/хар0000197

Choi, J. J., Laibson, D., \& Madrian, B. C. (2010). Why does the law of one price fail? An experiment on index mutual funds. The Review of Financial Studies, 23(4), 1405-1432. doi: 10.1093/rfs/hhp097

Choi, J. J., Laibson, D., Madrian, B. C., \& Metrick, A. (2009). Reinforcement learning and savings behavior. Journal of Finance, 64(6), 2515-2534. doi: 10.1111/j.1540-6261.2009.01509.x

Chung, D., Christopoulos, G. I., King-Casas, B., Ball, S. B., \& Chiu, P. H. (2015). Social signals of safety and risk confer utility and have asymmetric effects on observers' choices. Nature Neuroscience, 18(6), 912-916. doi: 10.1038/nn.4022

Daniel, K., Grinblatt, M., Titman, S., \& Wermers, R. (1997). Measuring mutual fund performance with characteristic-based benchmarks. The Journal of Finance, 52(3), 1035-1058.

Dayan, P. (2009). Goal-directed control and its antipodes. Neural Networks, 22(3), 213-219. doi: 10.1016/j.neunet.2009.03.004

Dayan, P., \& Niv, Y. (2008). Reinforcement learning: The good, the bad and the ugly. Current Opinion in Neurobiology, 18, 185-196. doi: 10.1016/j.conb.2008.08.003

Denrell, J. (2007). Adaptive learning and risk taking. Psychological Review, 114(1), 177-187. doi: 10.1037/0033-295X.114.1.177

Denrell, J., \& March, J. G. (2001). Adaptation as information restriction: The hot stove effect. Organization Science, 12(5), 523-538. doi: 10.1287/orsc.12.5.523.10092

Dhami, M. K., Hertwig, R., \& Hoffrage, U. (2004). The role of representative design in an ecological approach to cognition. Psychological Bulletin, 130(6), 959-988. doi: 10.1037/00332909.130.6.959

Dhar, R., \& Zhu, N. (2006). Up close and personal: Investor sophistication and the disposition effect. Management Science, 52(5), 726-740. doi: 10.1287/mnsc.1040.0473 
Dukes, W. P., English, P. C., \& Davis, S. M. (2006). Mutual fund mortality, 12B-1 fees, and the net expense ratio. Journal of Financial Research, 29(2), 235-252. doi: 10.1111/j.14756803.2006.00176.x

Edwards, W. (1961). Probability learning in 1000 trials. Journal of Experimental Psychology, 62(4), 385394. doi: $10.1037 /$ h0041970

Elton, E. J., Gruber, M. J., \& Busse, J. A. (2004). Are investors rational? Choices among index funds. Journal of Finance, 59(1), 261-288.

Ensthaler, L., Nottmeyer, O., Weizsäcker, G., \& Zankiewicz, C. (2018). Hidden skewness: On the difficulty of multiplicative compounding under random shocks. Management Science, 64(4), 1693-1706. doi: 10.1287/mnsc.2016.2618

Estrada-Mejia, C., de Vries, M., \& Zeelenberg, M. (2016). Numeracy and wealth. Journal of Economic Psychology, 54(1), 53-63. doi: 10.1016/j.joep.2016.02.011

Evans, R. B. (2010). Mutual fund incubation. The Journal of Finance, 65(4), 1581-1611.

Fama, E. F. (1970). Efficient capital markets: A review of theory and empirical work. The Journal of Finance, 25(2), 383-417.

Fama, E. F. (1995). Random walks in stock market prices. Financial Analysts Journal, 51(1), 75-80. doi: 10.2469/faj.v51.n1.1861

Fernandes, D., Lynch, J. G., \& Netemeyer, R. G. (2014). Financial literacy, financial education, and downstream financial behaviors. Management Science, 60(8), 1861-1883. doi: 10.1287/mnsc.2013.1849

Fiedler, K. (2000). Beware of samples! A cognitive-ecological sampling approach to judgment biases. Psychological Review, 107(4), 659-676. doi: 10.1037/0033-295X.107.4.659

Fillenbaum, S., Wallsten, T. S., Cohen, B. L., \& Cox, J. A. (1991). Some effects of vocabulary and communication task on the understanding and use of vague probability expressions. The American Journal of Psychology, 104(1), 35-60. doi: 10.2307/1422850

Fisch, J. E. (2010). Rethinking the regulation of securities intermediaries. University of Pennsy/vania Law Review, 158(7), 1961-2041.

Fisch, J. E., \& Wilkinson-Ryan, T. (2014). Why do retail investors make costly mistakes? An experiment on mutual fund choice. University of Pennsylvania Law Review, 162(3), 605-647. doi: $10.2139 /$ ssrn. 2086766

Fischhoff, B. (1998). Communicate unto others... Reliability Engineering and System Safety, 59(1), 6372. doi: 10.1016/S0951-8320(97)00120-8

Frino, A., \& Gallagher, D. R. (2002). Is index performance achievable? An analysis of Australian equity index funds. Abacus, 38(2), 200-214. doi: 10.1111/1467-6281.00105 
Frino, A., Gallagher, D. R., Neubert, A. S., \& Oetomo, T. N. (2004). Index design and implications for index tracking. The Journal of Portfolio Management, 30(2), 89-95. doi: 10.3905/jpm.2004.319934

Fu, W. T., \& Anderson, J. R. (2008). Dual learning processes in interactive skill acquisition. Journal of Experimental Psychology: Applied, 14(2), 179-191. doi: 10.1037/1076-898X.14.2.179

Gaissmaier, W., \& Schooler, L. J. (2008). The smart potential behind probability matching. Cognition, 109(3), 416-422. doi: 10.1016/j.cognition.2008.09.007

Ghazal, S., Cokely, E. T., \& Garcia-Retamero, R. (2014). Predicting biases in very highly educated samples: Numeracy and metacognition. Judgment and Decision Making, 9(1), 15-34.

Grinblatt, M., \& Titman, S. (1989). Mutual fund performance: An analysis of quarterly portfolio holdings. The Journal of Business, 62(3), 393-416.

Gureckis, T. M., \& Love, B. C. (2009a). Learning in noise: Dynamic decision-making in a variable environment. Journal of Mathematical Psychology, 53(3), 180-193. doi: 10.1016/j.jmp.2009.02.004

Gureckis, T. M., \& Love, B. C. (2009b). Short-term gains, long-term pains: How cues about state aid learning in dynamic environments. Cognition, 113, 293-313. doi: 10.1016/j.cognition.2009.03.013

Hadar, L., Sood, S., \& Fox, C. R. (2013). Subjective knowledge in consumer financial decisions. Journal of Marketing Research, 50(3), 303-316. doi: 10.1509/jmr.10.0518

Harvey, N. (1995). Why are judgments less consistent in less predictable task situations? Organizational Behavior and Human Decision Processes, 63(3), 247-263. doi: 10.1006/obhd.1995.1077

Harvey, N., Ewart, T., \& West, R. (1997). Effects of data noise on statistical judgement. Thinking \& Reasoning, 3(2), 111-132. doi: 10.1080/135467897394383

Haslem, J. A., Baker, H. K., \& Smith, D. M. (2008). Performance and characteristics of actively managed retail equity mutual funds with diverse expense ratios. Financial Services Review, 17, 49-68. doi: 10.2139/ssrn.1128983

Hertwig, R., Barron, G., Weber, E. U., \& Erev, I. (2004). Decisions from experience and the effect of rare events in risky choice. Psychological Science, 15(8), 534-539. doi: 10.1111/j.09567976.2004.00715.x

Hertwig, R., \& Pleskac, T. J. (2010). Decisions from experience: Why small samples? Cognition, 115, 225-237. doi: 10.1016/j.cognition.2009.12.009 
Hills, T. T., Noguchi, T., \& Gibbert, M. (2013). Information overload or search-amplified risk? Set size and order effects on decisions from experience. Psychonomic Bulletin \& Review, 20, 10231031. doi: $10.3758 / s 13423-013-0422-3$

Hogarth, R. M., \& Einhorn, H. J. (1992). Order effects in belief updating: The belief-adjustment model. Cognitive Psychology, 24, 1-55. doi: 10.1016/0010-0285(92)90002-J

Houge, T., \& Wellman, J. (2007). The use and abuse of mutual fund expenses. Journal of Business Ethics, 70(1), 23-32. doi: 10.1007/s10551-006-9077-6

Investment Company Institute. (2019). 2019 Investment Company Fact Book (59th ed.). Retrieved from www.ici.org/pdf/2019\{_\}factbook.pdf

Israelsen, C. L., \& Cogswell, G. F. (2007). The error of tracking error. Journal of Asset Management, 7(6), 419-424. doi: 10.1057/palgrave.jam.2250051

Jain, P. C., \& Wu, J. S. (2000). Truth in mutual fund advertising: Evidence on future performance and fund flows. Journal of Finance, 2(2), 937-958.

Kahneman, D., \& Tversky, A. (1972). Subjective probability: A judgment of representativeness. Cognitive Psychology, 3, 430-454. doi: 10.1016/0010-0285(72)90016-3

Kareev, Y. (2000). Seven (indeed, plus or minus two) and the detection of correlations. Psychological Review, 107(2), 397-403. doi: 10.1037//0033-295x.107.2.397

Koehler, D. J., \& James, G. (2010). Probability matching and strategy availability. Memory \& Cognition, 38, 667-676. doi: 10.3758/MC.38.6.667

Koehler, J. J., \& Mercer, M. (2009). Selection neglect in mutual fund advertisements. Management Science, 55(7), 1107-1121. doi: 10.1287/mnsc.1090.1013

Lee, M. D., Zhang, S., Munro, M., \& Steyvers, M. (2011). Psychological models of human and optimal performance in bandit problems. Cognitive Systems Research, 12, 164-174. doi: 10.1016/j.cogsys.2010.07.007

Lejarraga, T. (2010). When experience is better than description: Time delays and complexity. Journal of Behavioral Decision Making, 23, 100-116. doi: 10.1002/bdm.666

Liang, Y., Ramchander, S., \& Sharma, J. L. (1995). The performance of stocks: Professional versus dartboard picks. Journal of Financial and Strategic Decisions, 8(1), 55-63.

Lohrenz, T., Bhatt, M., Apple, N., \& Montague, P. R. (2013). Keeping up with the Joneses: Interpersonal prediction errors and the correlation of behavior in a tandem sequential choice task. PLOS Computational Biology, 9(10), e1003275. doi: 10.1371/journal.pcbi.1003275

Lopes, L. L. (1982). Doing the impossible: A note on induction and the experience of randomness. Journal of Experimental Psychology: Learning, Memory, and Cognition, 8(6), 626-636. doi: 10.1037/0278-7393.8.6.626 
Malkiel, B. G. (1995). Returns from investing in equity mutual funds 1971 to 1991 . The Journal of Finance, 50(2), 549-572. doi: 10.2307/2329419

Malkiel, B. G. (1999). A random walk down Wall Street. New York: W.W.Norton.

Malkiel, B. G. (2003). The efficient market hypothesis and its critics. Journal of Economic Perspectives, 17(1), 59-82. doi: 10.1257/089533003321164958

Mauck, N., \& Salzsieder, L. (2017). Diversification bias and the law of one price: An experiment on index mutual funds. Journal of Behavioral Finance, 18, 45-53. doi: $10.1080 / 15427560.2017 .1276067$

Mebane, W. R., \& Sekhon, J. S. (2011). Genetic optimization using derivatives: The rgenoud package for R. Journal of Statistical Software, 42(11), 1-26. doi: 10.18637/jss.v042.i11

Mercer, M., Palmiter, A. R., \& Taha, A. E. (2010). Worthless warnings? Testing the effectiveness of disclaimers in mutual fund advertisements. Journal of Empirical Legal Studies, 7(3), 429-459. doi: 10.1111/j.1740-1461.2010.01184.x

Mosenhauer, M., Newall, P. W. S., \& Walasek, L. (2021). The stock market as a casino : Associations between costly excessive stock market trading and problem gambling. PsyArXiv Preprints. doi: 10.31234/osf.io/zqe9s

Newall, P. W. S. (2016). Downside financial risk is misunderstood. Judgment and Decision Making, 11(5), 416-423.

Newall, P. W. S., \& Love, B. C. (2015). Nudging investors big and small toward better decisions. Decision, 2(4), 319-326. doi: 10.1037/dec0000036

Newall, P. W. S., \& Parker, K. N. (2019). Improved mutual fund investment choice architecture. Journal of Behavioral Finance, 20(1), 96-106. doi: 10.1080/15427560.2018.1464455

Osman, M., McLachlan, S., Fenton, N. E., Neil, M., Löfstedt, R., \& Meder, B. (2020). Learning from behavioural changes that fail. Trends in Cognitive Sciences. doi: 10.1016/j.tics.2020.09.009

Otto, A. R., Taylor, E. G., \& Markman, A. B. (2011). There are at least two kinds of probability matching: Evidence from a secondary task. Cognition, 118, 274-279. doi: 10.1016/j.cognition.2010.11.009

Payne, J. W. (1976). Task complexity and contingent processing in decision making: An information search and protocol analysis. Organizational Behavior and Human Decision Processes, 16, 366-387. doi: 10.1016/0030-5073(76)90022-2

Payne, J. W., Bettman, J. R., \& Johnson, E. J. (1988). Adaptive strategy selection in decision making. Journal of Experimental Psychology: Learning, Memory, and Cognition, 14(3), 534-552. doi: 10.1037/0278-7393.14.3.534 
Petajisto, A. (2013). Active share and mutual fund performance. Financial Analysts Journal, 69(4), 7393. doi: 10.2469/faj.v69.n4.7

Plonsky, O., \& Erev, I. (2017). Learning in settings with partial feedback and the wavy recency effect of rare events. Cognitive Psychology, 93, 18-43. doi: 10.1016/j.cogpsych.2017.01.002

Plonsky, O., Teodorescu, K., \& Erev, I. (2015). Reliance on small samples, the wavy recency effect, and similarity-based learning. Psychological Review, 122(4), 621-647. doi: 10.1037/a0039413

Pontari, B. A., Stanaland, A. J. S., \& Smythe, T. (2009). Regulating information disclosure in mutual fund advertising in the United States: Will consumers utilize cost information? Journal of Consumer Policy, 32, 333-351. doi: 10.1007/s10603-009-9107-8

Rakow, T., \& Miler, K. (2009). Doomed to repeat the successes of the past: History is best forgotten for repeated choices with nonstationary payoffs. Memory \& Cognition, 37, 985-1000. doi: 10.3758/MC.37.7.985

Rao, A. R. (2005). The quality of price as a quality cue. Journal of Marketing Research, 42, 401-405. doi: 10.1509/jmkr.2005.42.4.401

Ratcliff, R., \& Smith, P. L. (2010). Perceptual discrimination in static and dynamic noise: The temporal relation between perceptual encoding and decision making. Journal of Experimental Psychology: General, 139(1), 70-94. doi: 10.1037/a0018128

Rescorla, R. A., \& Wagner, A. R. (1972). A theory of Pavlovian conditioning: Variations in the effectiveness of reinforcement and non-reinforcement. In A. H. Black \& W. F. Prokasy (Eds.), Classical conditioning 2: Current research and theory (pp. 64-99). New York: AppletonCentury-Crofts.

Rieskamp, J. (2006). Positive and negative recency effects in retirement savings decisions. Journal of Experimental Psychology: Applied, 12(4), 233-250. doi: 10.1037/1076-898X.12.4.233

Shanks, D. R., Tunney, R. J., \& McCarthy, J. D. (2002). A re-examination of probability matching and rational choice. Journal of Behavioral Decision Making, 15, 233-250. doi: 10.1002/bdm.413

Shapira, Z., \& Venezia, I. (2001). Patterns of behavior of professionally managed and independent investors. Journal of Banking and Finance, 25, 1573-1587. doi: 10.1016/S03784266(00)00139-4

Shefrin, H. (2009). Behavioralizing finance. Foundations and Trends in Finance, 4, 1-184. doi: $10.1561 / 0500000030$

Shefrin, H., \& Statman, M. (1985). The disposition to sell winners too early and ride losers too long: Theory and evidence. The Journal of Finance, 40(3), 777-790.

Siegel, J. J. (1992). The equity premium: Stock and bond returns since 1802. Financial Analysts Journal, 48(1), 28-38. doi: 10.2469/faj.v48.n1.28 
Sims, T., Raposo, S., Bailenson, J. N., \& Carstensen, L. L. (2020). The future is now: Age-progressed images motivate community college students to prepare for their financial futures. Journal of Experimental Psychology: Applied. doi: 10.1037/xap0000275

Sirri, E. R., \& Tufano, P. (1998). Costly search and mutual fund flows. The Journal of Finance, 53(5), $1589-1622$.

Soll, J. B., Keeney, R. L., \& Larrick, R. P. (2013). Consumer misunderstanding of credit card use, payments, and debt: Causes and solutions. Journal of Public Policy \& Marketing, 32(1), 66-81. doi: 10.1509/jppm.11.061

Speekenbrink, M., \& Konstantinidis, E. (2015). Uncertainty and exploration in a restless bandit problem. Topics in Cognitive Science, 7, 351-367. doi: 10.1111/tops.12145

Stango, V., \& Zinman, J. (2009). Exponential growth bias and household finance. Journal of Finance, 64(6), 2807-2849. doi: 10.1111/j.1540-6261.2009.01518.x

Stewart, E. (2020). Who gets to be reckless on Wall Street? Vox. Retrieved 2021-01-06, from www.vox.com/business-and-finance/2020/7/9/21314119/stock-market-day-trading-redditdave-portnoy-barstool-robinhood

Sutton, R., \& Barto, A. G. (1998). Reinforcement learning: An introduction. Cambridge, MA: MIT Press. Tunney, R. J., \& Shanks, D. R. (2002). A re-examination of melioration and rational choice. Journal of Behavioral Decision Making, 15(4), 291-311. doi: 10.1002/bdm.415

Tversky, A., \& Kahneman, D. (1971). Belief in the law of small numbers. Psychological Bulletin, 76(2), 105-110. doi: 10.1037/h0031322

Tykocinski, O. E., Israel, R., \& Pittman, T. S. (2004). Inaction inertia in the stock market. Journal of Applied Social Psychology, 34(6), 1166-1175. doi: 10.1111/j.1559-1816.2004.tb02001.x

Tykocinski, O. E., Pittman, T. S., \& Tuttle, E. E. (1995). Inaction inertia: Foregoing future benefits as a result of an initial failure to act. Journal of Personality and Social Psychology, 68(5), 793-803. doi: 10.1037/0022-3514.68.5.793

Volkman, D. A., \& Wohar, M. E. (1995). Determinants of persistence in relative performance of mutual funds. Journal of Financial Research, 18(4), 415-430.

Wagenmakers, E.-J., \& Farrell, S. (2004). AIC model selection using Akaike weights. Psychonomic Bulletin \& Review, 11, 192-196. doi: 10.3758/BF03206482

Wallsten, T. S., Budescu, D. V., Rapoport, A., Zwick, R., \& Forsyth, B. (1986). Measuring the vague meanings of probability terms. Journal of Experimental Psychology: General, 115(4), 348-365. doi: 10.1037/0096-3445.115.4.348 
Weiss-Cohen, L., Konstantinidis, E., Speekenbrink, M., \& Harvey, N. (2016). Incorporating conflicting descriptions into decisions from experience. Organizational Behavior and Human Decision Processes, 135, 55-69. doi: 10.1016/j.obhdp.2016.05.005

Weiss-Cohen, L., Konstantinidis, E., Speekenbrink, M., \& Harvey, N. (2018). Task complexity moderates the influence of descriptions in decisions from experience. Cognition, 170, 209-227. doi: 10.1016/j.cognition.2017.10.005

Wilcox, R. T. (2003). Bargain hunting or star gazing? Investors' preferences for stock mutual funds. The Journal of Business, 76(4), 645-663. doi: 10.1086/377034

Worthy, D. A., Hawthorne, M. J., \& Otto, A. R. (2013, apr). Heterogeneity of strategy use in the lowa gambling task: A comparison of win-stay/lose-shift and reinforcement learning models. Psychonomic Bulletin \& Review, 20(2), 364-371. doi: 10.3758/s13423-012-0324-9

Worthy, D. A., \& Maddox, W. T. (2012). Age-based differences in strategy use in choice tasks. Frontiers in Neuroscience, 5, 1-10. doi: 10.3389/fnins.2011.00145

Worthy, D. A., Pang, B., \& Byrne, K. A. (2013). Decomposing the roles of perseveration and expected value representation in models of the lowa Gambling Task. Frontiers in Psychology, 4, 640. doi: 10.3389/fpsyg.2013.00640

Yechiam, E., \& Busemeyer, J. R. (2005). Comparison of basic assumptions embedded in learning models for experience-based decision making. Psychonomic Bulletin \& Review, 12(3), 387402. doi: $10.3758 / B F 03193783$

Yechiam, E., \& Busemeyer, J. R. (2008). Evaluating generalizability and parameter consistency in learning models. Games and Economic Behavior, 63, 370-394. doi: 10.1016/j.geb.2007.08.011

Yechiam, E., Erev, I., \& Gopher, D. (2001). On the potential value and limitations of emphasis change and other exploration-enhancing training methods. Journal of Experimental Psychology: Applied, 7(4), 277-285. doi: 10.1037//1076-898x.7.4.277

Yechiam, E., \& Ert, E. (2007). Evaluating the reliance on past choices in adaptive learning models. Journal of Mathematical Psychology, 51, 75-84. doi: 10.1016/j.jmp.2006.11.002

Yechiam, E., \& Rakow, T. (2012). The effect of foregone outcomes on choices from experience. Experimental Psychology, 59, 55-67. doi: 10.1027/1618-3169/a000126

Yu, A. J., \& Cohen, J. D. (2009). Sequential effects: Superstition or rational behavior? Advances in Neural Information Processing Systems 21 - Proceedings of the 2008 Conference, 1873-1880.

Zweig, J. (2020). I started trading hot stocks on Robinhood. Then I couldn't stop. The Wall Street Journal. Retrieved 2021-01-06, from www.wsj.com/articles/robinhood-day-trade-i-startedtrading-hot-stocks-then-i-couldnt-stop-11607095765 


\section{Appendix A Analysis of Variance (ANOVA) results}

Table A1 contains the ANOVA results of the linear regressions used in the main statistical analyses, using the treatment contrast for disclaimer and after mean-centering the continuous variables. The pre-registered ANOVA table, using a Helmert contrast and raw untransformed variables, is nearly indistinguishable from the one below, as these changes affect the scale and magnitude coefficients of the regressions, but not their variance (the pre-registered ANOVA tables are in OSF). Two p-values changed at the third decimal figure, which does not affect any of the conclusions. As preregistered, these are Type-II ANOVA results, which means that the main effects are estimated in isolation from their interactions. This is a different approach to a regression table, which considers the main effects after controlling for their interactions (similar to a Type-III ANOVA), therefore the significance of the main effects might differ. However, none of the conclusions would change if we extracted our results solely from these ANOVA tables instead of the regression tables used in the main manuscript, as the interpretation of the results remain the same.

\section{[TABLE A1 HERE]}

\section{Appendix B Cognitive modelling}

Because the task employed in the current research involved a binary choice between two options, the models only needed to estimate the probability of selecting one of the funds at each trial, as the probability for choosing the other fund could be simply extracted as the compliment of the modelled probability. We therefore define all the models around the probability of choosing the lowfee fund, $\operatorname{Pr}\left[F_{\text {low }}(t)\right]$.

\section{B.1 The two base models}

The random model chooses each fund at time $t$ with probability $50 \%$, therefore the probability of selecting the low-fee fund is always:

$$
\operatorname{Pr}\left[F_{\text {low }}(t)\right]=0.5
$$

The low-fee fund model chooses the low-fee fund at time $t$ always with probability $100 \%$ :

$$
\operatorname{Pr}\left[F_{\text {low }}(t)\right]=1
$$

\section{B.2 Reinforcement learning model}

The expectancy-valence (EV) delta-rule reinforcement learning model uses all past available information when choosing a fund (Yechiam \& Busemeyer, 2005). It has two free parameters, $\phi$ and 
$\theta$, described below. The model starts by updating the expectancy value of each fund $j$ (low-fee or highfee) at every trial $t, E_{j}(t)$, as follows:

$$
E_{j}(t)=E_{j}(t-1)+\phi \cdot\left[r_{j}(t)-E_{j}(t-1)\right]
$$

where $r_{j}(t)$ is the observed return (past performance) of fund $j$ at time $t$, and $\phi$ is the free learning parameter, which is allowed to vary between zero and one. For values of $\phi$ closer to zero, the model gives relatively equal weight to all observations, while for values closer to one, the model gives higher weights to more recent observations. The expectancies start at zero in the first trial.

After the expectancies are updated, the model chooses the low-fee fund at trial $t$ according to a soft-max ratio choice rule which chooses the low-fee fund in accordance to the relative ratio of its expectancy when compared to the high-fee fund's expectancy:

$$
\operatorname{Pr}\left[F_{\text {low }}(t)\right]=\frac{e^{\theta \cdot E_{\text {low }}(t)}}{e^{\theta \cdot E_{\text {low }}(t)}+e^{\theta \cdot E_{\text {high }}(t)}}
$$

where $\theta$ is the choice sensitivity free parameter, $(0 \leq \theta \leq 5)$. If $\theta=0$, the model randomly guesses between the expectancies regardless of their values, while higher values of $\theta$ will lead to more deterministic maximization behavior.

\section{B.3 Win-stay-lose-shift model}

The win-stay-lose-shift (WSLS) model uses only the information from the previous trial when choosing the fund for the next trial. The model selects the fund in trial $t$ according to: (a) the fund selected in trial $t-1$; (b) if the selected fun had higher (win) or lower returns (loss) than the other fund at trial $t-1$; and (c) two free parameters, the probability to stay with the same fund given a win $(\operatorname{Pr}[$ stay/win]) and the probability to shift to the other fund given a loss (Pr[shift/loss]), both of which ranged from zero to one.

To parametrize the above mechanism, the probability of staying with the low-fee fund in trial $t$, after having selected it in trial $t-1$, given that the low-fee fund "won" in comparison to the highfee fund in trial $t-1$, is defined as:

$$
\operatorname{Pr}\left[\mathrm{F}_{\text {low }}(\mathrm{t}) \mid \delta(\mathrm{t}-1)=1 \& \mathrm{rlow}_{\text {low }}(\mathrm{t}-1)>\mathrm{r}_{\text {high }}(\mathrm{t}-1)\right]=\operatorname{Pr}[\text { stay } \mid \text { win }]
$$


where $\delta(t-1)$ is equal to one if the low-fee fund was chosen in trial $t-1$, zero if the high-fee fund was chosen (in this case, the low-fee fund was chosen), and $r_{\text {low }}(t-1)$ and $r_{\text {high }}(t-1)$ are the returns of the low-fee and high-fee fund in the previous trial, respectively.

The probability of shifting away from the low-fee fund in trial $t$ (i.e., choosing the high-fee fund), after having selected it in trial $t-1$, given that the low-fee fund "lost" in comparison to the highfee fund in trial $t-1$, is defined as:

$$
\operatorname{Pr}\left[F_{\text {high }}(t) \mid \delta(t-1)=1 \& r_{\text {low }}(t-1)<r_{\text {high }}(t-1)\right]=\operatorname{Pr}[\text { shift } \mid \text { loss }]
$$

\section{B.4 Model evaluation and results}

The competitor RL and WSLS models were fitted against the observed experimental behavior at individual level using a one-step-ahead prediction method (Yechiam \& Busemeyer, 2008; Yechiam \& Ert, 2007). We used the matrices of actual returns observed for each individual, and the arrays of choices they made (in order to determine if they were shifting or staying with their previous choice for the WSLS model), at each trial, and predicted the next trial. To keep the cognitive modelling analysis consistent with the statistical analysis of trials 2-60, we also restricted the cognitive modelling to only those trials, excluding the first trial. We used the genoud optimization function (Mebane \& Sekhon, 2011) in $R$, and the free parameters were evaluated in increments of 0.001 . Model predictions were compared against observed human behavior using log-likelihood minimization:

$$
L L=\sum_{t=2}^{60} \ln \left[\operatorname{Pr}\left[F_{\text {low }}(t)\right] \cdot \delta(t)\right]+\ln \left(\left[1-\operatorname{Pr}\left[F_{\text {low }}(t)\right] \cdot[1-\delta(t)]\right)\right.
$$

where $\operatorname{Pr}\left[F_{\text {low }}(t)\right]$ is the probability of selecting the low-fee fund at trial $t$, and $\delta(t)$ is equal to one if the low-fee fund was chosen in trial $t$, zero if the high-fee fund was chosen. As the logarithm of zero is minus infinity, we restricted $\operatorname{Pr}\left[F_{\text {low }}(t)\right]$ to a minimum of 0.001 and a maximum of 0.999 .

In order to compare the models, we used Akaike Information Criteria (AIC) weights (Wagenmakers \& Farrell, 2004), which penalizes the two decision models for having more parameters (two) than the base models (zero). The winning fund was the one with the lowest AIC:

$$
A I C=-2 L L+2 k,
$$

where $k$ is the number of parameters in the model. In our case, it was either zero (for the two simpler models) or two (for the competitor models). The mean AIC for each model (lower is better), and the 
mean best fitting parameters for each competitor model are show in Table B1 (the individual best fitting parameters and AIC for each participant for each model are in OSF). Both competitor models had lower AIC than the random model, although it is clear that the WSLS model was the winner overall. The low-fee fund appear to have done poorly, because it did not fit the behavior of most participants, but for $23 \%$ of participants it fitted behavior the best, with the lowest AIC for those individuals. The random model's AIC has no deviance because the LL is the same for all participants, due to the 50/50 random behavior it predicts.

\section{[TABLE B1 HERE]}

\section{Appendix C Instructions}

Reproduced below are the full set of instructions for the experiments, which were displayed before the task started. The first and last items were removed after the first selection was made, but the remaining six middle items remained on screen throughout the main fund selection task. Italics as in the original.

The instructions differed slightly between the experiments. For Experiments 1a and 2, they were based on passive funds which closely match the index:

- Two buttons will be shown below. They represent two mutual funds in which you can invest. Mutual funds are used to invest in a diversified manner. They pool the money of many investors together to buy many individual assets.

- The two funds below are very similar. Both invest in all S\&P 500 stocks, which are the 500 largest companies listed on the New York Stock Exchange. Their aim is the same: to match the S\&P 500 index as closely as possible.

- You will be asked to choose between the two funds for many months. Returns shown are based on actual historical monthly data from the S\&P 500 index. You should aim to maximize your returns, to get a higher bonus.

- Mutual funds charge management fees, shown below each fund as \% of total assets charged per year. You pay the fees shown to invest in each fund, regardless of performance.

- After each choice you make, returns for that month will be shown, net of fees (after fees have been taken off), for both funds. $1 / 12$ of the annual fees are deducted from the returns every month.

- The returns from the fund you choose will accumulate towards your bonus. Each month's positive returns will be added, and negative returns will be taken off. You will get $\$ 1$ in bonus for every $10 \%$ accumulated. 
- At the start, you will also be shown the previous historical returns for each fund for the one year period before you can start investing in each fund. These will not be added to your bonus.

For Experiment $1 \mathrm{~b}$ the instructions were changed slightly to reflect that the funds are active funds. The second and third items were changed to the ones below, while the other items remained the same:

- The two funds below are similar. Both actively invest in selected S\&P 500 stocks, which are the 500 largest companies listed on the New York Stock Exchange. Their aim is the same: to outperform the S\&P 500 index by as much as possible.

- You will be asked to choose between the two funds for many months. Returns shown are based on actual historical monthly data. You should aim to maximize your returns, to get a higher bonus. 
A) Before first trial

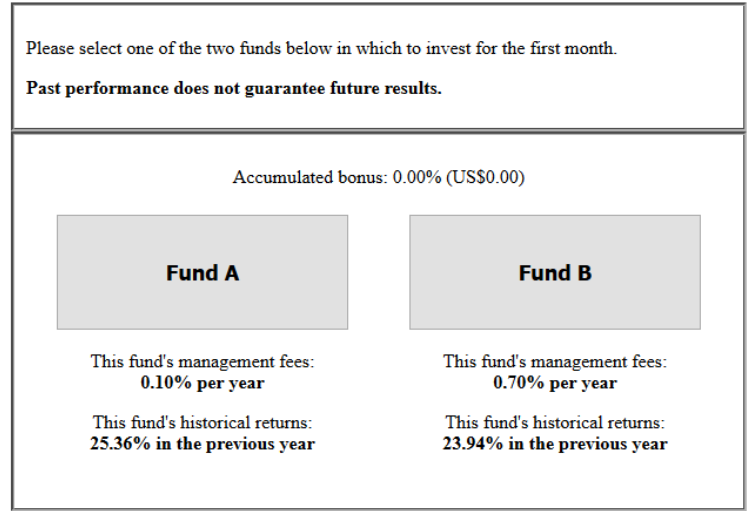

B) After first trial

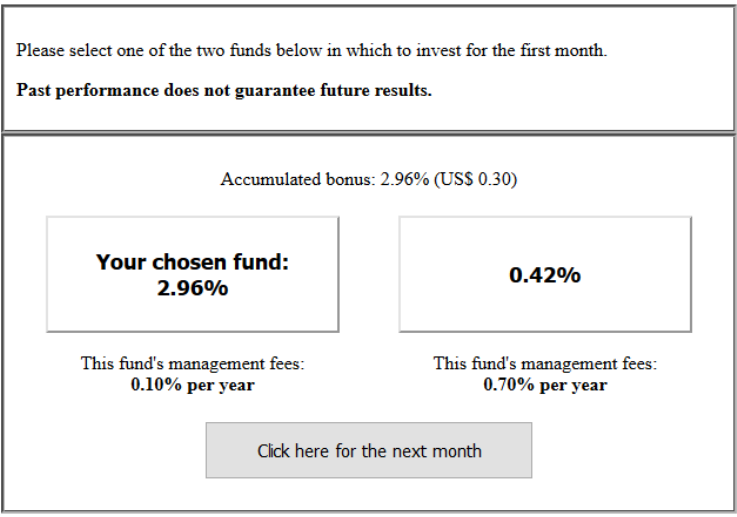

Figure 1. Screenshots in the standard disclaimer condition of Experiment 1a. (A) Before the first trial, with historical past returns displayed. (B) After the first selection has been made. In this example the participant has chosen Fund $A$. The positioning of the funds was randomized, shown here with the lowfee fund on the left and the high-fee fund on the right. 
A) Experiment 1a: Experienced investors and index-tracking funds
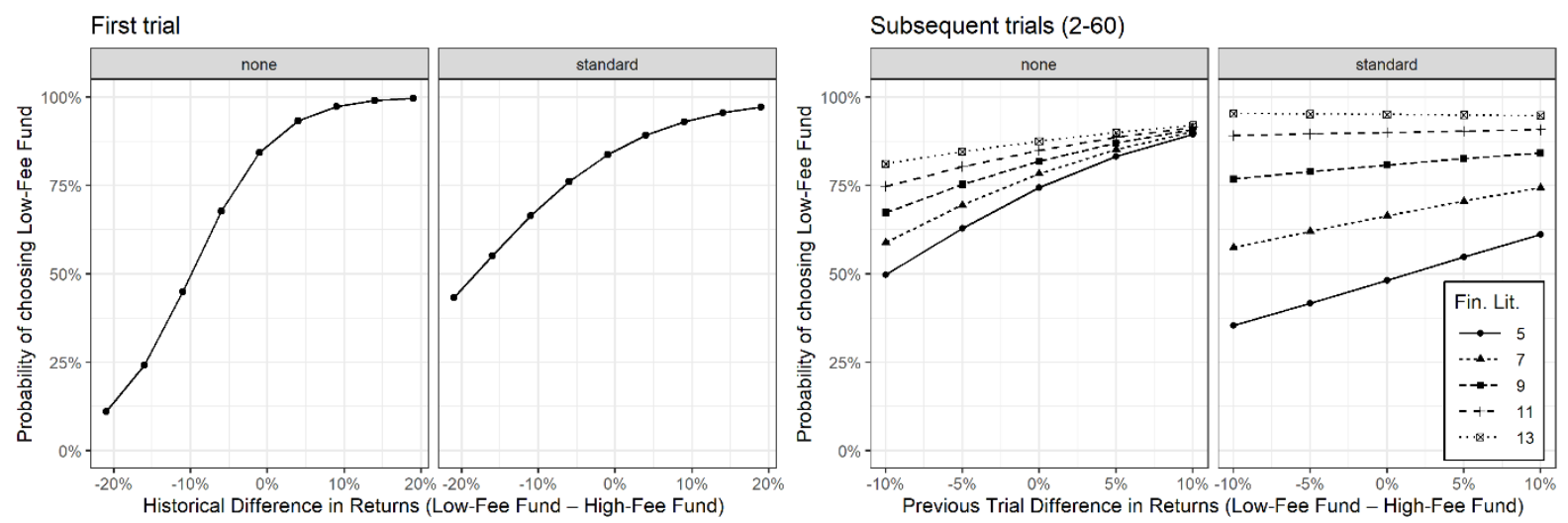

B) Experiment 1b: Experienced investors and actively managed funds
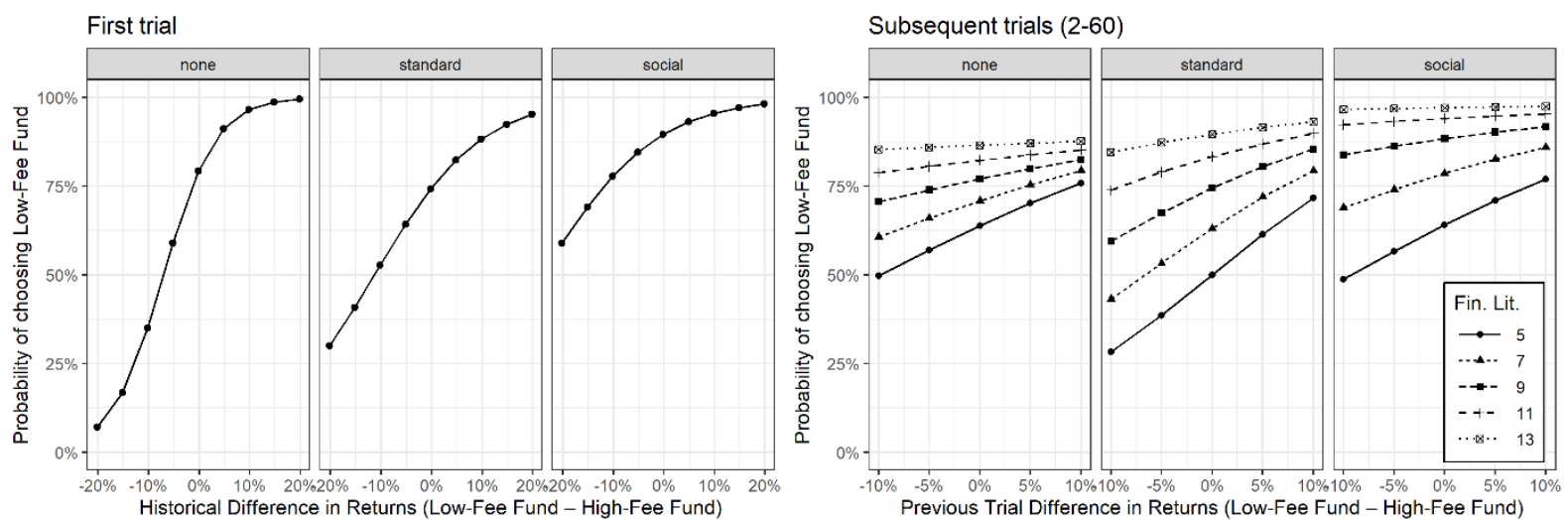

C) Experiment 2: Inexperienced investors and index-tracking funds
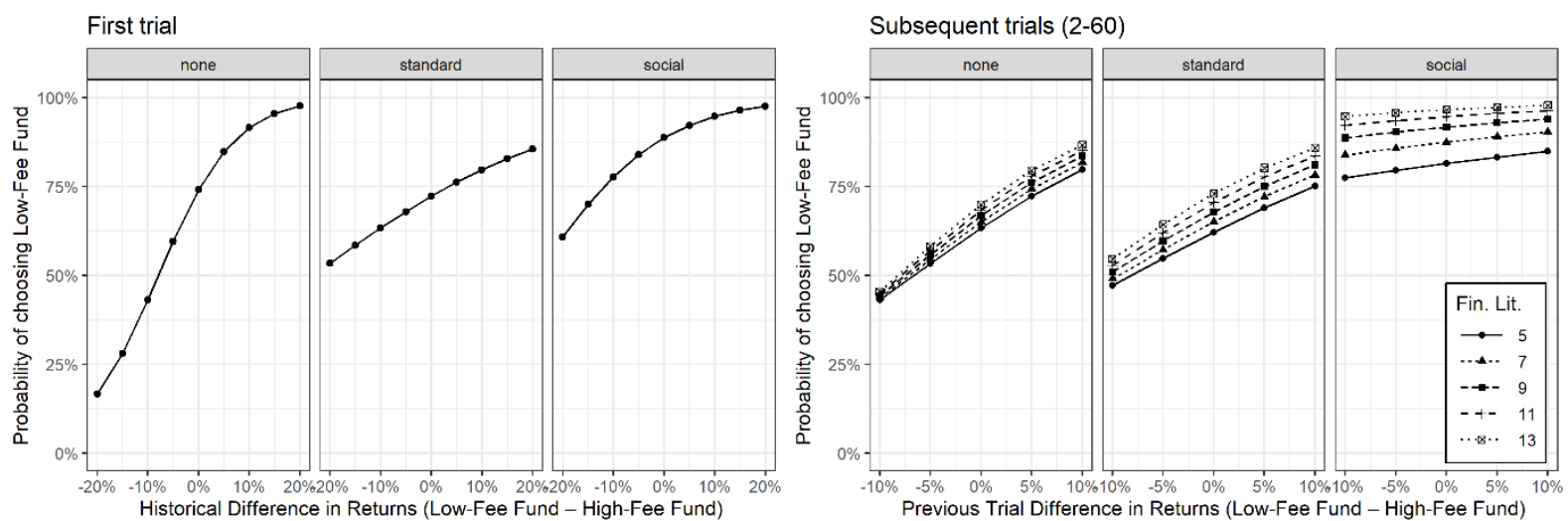

Figure 2. Experimental results according to disclaimer and financial literacy. The differences shown were calculated as returns from the low-fee fund minus the high-fee fund at each period. Positive values equate to the low-fee fund outperforming the high-fee fund by that amount. The slope of the curves represent chasing of past performance: the steeper the slope, the more participants' behaviors were sensitive to past performance. 
Table 1. Regression coefficients (log-odds) of the different analyses (standard errors in brackets). Trial number, financial literacy scores, and difference in returns are mean-centered. Trial numbered was also divided by 100. The difference in returns for the first trial analyses (A) are the differences in 12-month historical returns, while for the subsequent trial analyses $(B)$ they are the differences in returns in the previous trial. Positive differences indicate that the low-fee fund outperformed the high-fee fund. The disclaimer coefficients are shown in relation to the control condition of nodisclaimer (treatment contrast coding).

Selections from Low-fee Fund
(A) First Trial
(B) Subsequent trials

\begin{tabular}{|c|c|c|c|c|c|c|}
\hline & & & & & & \\
\hline & Exp. 1a & Exp. $1 b$ & Exp. 2 & Exp. 1a & Exp. 1b & Exp. 2 \\
\hline Trial number $(\div 100)$ & & & & $1.03 * * *$ & $0.60 * * *$ & $0.80 * * *$ \\
\hline & & & & $(0.34)$ & $(0.23)$ & $(0.21)$ \\
\hline Disclaimer=social & & $0.78^{* *}$ & $1.01 * * *$ & & $0.98 * * *$ & $1.48^{* * *}$ \\
\hline & & $(0.36)$ & $(0.31)$ & & $(0.25)$ & $(0.19)$ \\
\hline Disclaimer=standard & -0.14 & -0.30 & -0.10 & 0.22 & -0.05 & 0.02 \\
\hline & $(0.34)$ & $(0.30)$ & $(0.25)$ & $(0.28)$ & $(0.25)$ & $(0.18)$ \\
\hline Difference in returns & $18.82 * * *$ & $19.62 * * *$ & $13.30 * * *$ & $7.02 * * *$ & $2.89 * * *$ & $8.97 * * *$ \\
\hline & (3.12) & $(2.83)$ & $(2.35)$ & $(0.95)$ & $(0.71)$ & $(0.81)$ \\
\hline Financial literacy & 0.04 & 0.10 & 0.06 & 0.11 & $0.16^{*}$ & 0.04 \\
\hline & $(0.07)$ & $(0.08)$ & $(0.06)$ & $(0.07)$ & $(0.07)$ & $(0.05)$ \\
\hline Discl.=social $\times$ Difference & & $-10.69 * * *$ & -5.20 & & 0.50 & $-5.81 * * *$ \\
\hline & & (3.52) & (3.35) & & $(1.04)$ & $(1.26)$ \\
\hline Discl.=standard $\times$ Difference & $-9.31^{* *}$ & $-10.07 * * *$ & $-9.20 * * *$ & $-5.45 * * *$ & $3.52 * * *$ & $-2.18^{*}$ \\
\hline & $(3.78)$ & (3.37) & $(2.96)$ & $(1.30)$ & (0.99) & $(1.15)$ \\
\hline Discl.=social $\times$ Fin. Lit. & & 0.04 & -0.01 & & $0.20 *$ & $0.19 * * *$ \\
\hline & & $(0.12)$ & $(0.09)$ & & $(0.10)$ & $(0.06)$ \\
\hline Discl.=standard $\times$ Fin. Lit. & 0.14 & 0.005 & -0.04 & $0.27^{* * *}$ & 0.11 & 0.02 \\
\hline & $(0.10)$ & $(0.10)$ & $(0.09)$ & $(0.10)$ & $(0.09)$ & $(0.07)$ \\
\hline Difference $\times$ Fin. Lit. & 0.92 & 0.66 & 0.10 & $-0.73 * * *$ & $-0.60 * * *$ & 0.25 \\
\hline & $(0.62)$ & $(0.47)$ & $(0.44)$ & $(0.24)$ & $(0.16)$ & $(0.18)$ \\
\hline Constant & $1.87^{* * *}$ & $1.38 * * *$ & $1.05^{* * *}$ & $1.62 * * *$ & $1.34 * * *$ & $0.66^{* * *}$ \\
\hline & $(0.26)$ & $(0.24)$ & $(0.19)$ & $(0.22)$ & $(0.18)$ & $(0.14)$ \\
\hline Participants & 400 & 599 & 596 & 400 & 599 & 596 \\
\hline Observations & 400 & 599 & 596 & 23,600 & 35,341 & 35,164 \\
\hline $\mathrm{R}^{2}$ & 0.24 & 0.30 & 0.15 & 0.78 & 0.70 & 0.66 \\
\hline
\end{tabular}


Table 2. Model fitting results. Number of participants in each condition which best fit each cognitive model (percentages of columns in brackets). The best fitting model overall was the WSLS model. The social disclaimer significantly increased the number of participants best fitting the low-fee model.

\begin{tabular}{lcccc}
\hline & \multicolumn{3}{c}{ Disclaimer } & Total \\
\hline Model & None & Standard & Social & 195 \\
Landom model & 82 & 70 & 43 & $(12 \%)$ \\
& $(14 \%)$ & $(12 \%)$ & $(11 \%)$ & 373 \\
Low-fee model & 118 & 132 & 123 & $(23 \%)$ \\
& $(20 \%)$ & $(22 \%)$ & $(31 \%)$ & 293 \\
RL model & 108 & 125 & 60 & $(18 \%)$ \\
& $(18 \%)$ & $(21 \%)$ & $(15 \%)$ & 734 \\
& 294 & 269 & 171 & $(46 \%)$ \\
\hline Total & $(49 \%)$ & $(45 \%)$ & $(43 \%)$ & 1595 \\
\hline
\end{tabular}


Table A1. Type-II ANOVA tables of the linear regressions used in the main statistical analyses. This table shows the result using treatment contrasts for the variable Disclaimer, and mean-centering the variables Difference and Financial Literacy.

\begin{tabular}{|c|c|c|c|c|c|c|c|c|c|}
\hline & \multicolumn{3}{|c|}{ Experiment 1a } & \multicolumn{3}{|c|}{ Experiment $1 \mathrm{~b}$} & \multicolumn{3}{|c|}{ Experiment 2} \\
\hline & $\chi^{2}$ & df & $p$ & $\chi^{2}$ & df & $p$ & $\chi^{2}$ & df & $p$ \\
\hline \multicolumn{10}{|l|}{ First trial } \\
\hline Disclaimer & 0.79 & 1 & .375 & 26.57 & 2 & $<.001$ & 21.48 & 2 & $<.001$ \\
\hline Difference in returns & 76.83 & 1 & $<.001$ & 146.54 & 1 & $<.001$ & 53.87 & 1 & $<.001$ \\
\hline Financial literacy & 1.95 & 1 & .163 & 4.66 & 1 & .031 & 1.00 & 1 & .317 \\
\hline Disclaimer $\times$ Difference & 6.46 & 1 & .011 & 13.08 & 2 & .001 & 10.29 & 2 & .006 \\
\hline Disclaimer $\times$ Fin. Lit. & 1.96 & 1 & .162 & 0.14 & 2 & .933 & 0.20 & 2 & .906 \\
\hline Difference $\times$ Fin. Lit. & 2.12 & 1 & .145 & 1.94 & 1 & .163 & 0.05 & 1 & .822 \\
\hline \multicolumn{10}{|l|}{ Subsequent trials } \\
\hline Trial number & 9.03 & 1 & .003 & 6.84 & 1 & .009 & 13.88 & 1 & $<.001$ \\
\hline Disclaimer & 0.50 & 1 & .480 & 21.15 & 2 & $<.001$ & 79.83 & 2 & $<.001$ \\
\hline Difference in returns & 51.93 & 1 & $<.001$ & 121.52 & 1 & $<.001$ & 174.91 & 1 & $<.001$ \\
\hline Financial literacy & 18.68 & 1 & $<.001$ & 38.35 & 1 & $<.001$ & 17.44 & 1 & $<.001$ \\
\hline Disclaimer $\times$ Difference & 17.43 & 1 & $<.001$ & 14.69 & 2 & .001 & 21.19 & 2 & $<.001$ \\
\hline Disclaimer $\times$ Fin. Lit. & 6.79 & 1 & .009 & 3.88 & 2 & .144 & 10.68 & 2 & .005 \\
\hline Difference $\times$ Fin. Lit. & 9.47 & 1 & .002 & 14.10 & 1 & $<.001$ & 1.91 & 1 & .167 \\
\hline
\end{tabular}


Table B1. Best fit parameters for the competitor models, and AIC results (lower is better). Mean and $S D$ for all participants, and for those participants for whom each model was the best fitting one.

\begin{tabular}{llcccc}
\hline \multirow{2}{*}{ Model } & & All participants & \multicolumn{2}{c}{ Best fitting } \\
& & Mean & (SD) & Mean & (SD) \\
\hline RL & Learning Rate: $\phi$ & 0.20 & $(0.31)$ & 0.19 & $(0.29)$ \\
& Choice sensitivity: $\theta$ & 2.66 & $(2.16)$ & 3.04 & $(1.93)$ \\
& Model fit: AIC & 72.79 & $(17.12)$ & 66.60 & $(13.77)$ \\
\hline \multirow{2}{*}{ WSLS } & Pr[Stay | Win] & 0.78 & $(0.22)$ & 0.76 & $(0.22)$ \\
& Pr[Shift | Loss] & 0.29 & $(0.24)$ & 0.31 & $(0.23)$ \\
& Model fit: AIC & 51.67 & $(30.75)$ & 56.68 & $(22.56)$ \\
\hline Low-fee & Model fit: AIC & 278.69 & $(232.90)$ & 3.56 & $(8.03)$ \\
\hline Random & Model fit: AIC & 81.79 & $(0)$ & 81.79 & $(0)$ \\
\hline
\end{tabular}

